\title{
Uncoupling protein 3 deficiency impairs myocardial fatty acid oxidation and contractile recovery following ischemia/reperfusion
}

\author{
Kristin S. Edwards ${ }^{1,2,3} \cdot$ Sadia Ashraf ${ }^{1,2,3} \cdot$ Tyler M. Lomax $^{1,2,3} \cdot$ Jessica M. Wiseman ${ }^{1,2,3} \cdot$ Michael E. Hall $^{1,2,3,4}$. \\ Fabio N. Gava ${ }^{1,2} \cdot$ John E. Hall ${ }^{1,2} \cdot$ Jonathan P. Hosler ${ }^{5} \cdot$ Romain Harmancey $^{1,2,3}$ (1)
}

Received: 28 June 2018 / Accepted: 23 October 2018 / Published online: 29 October 2018

(c) The Author(s) 2018

\begin{abstract}
Patients with insulin resistance and type 2 diabetes have poor cardiac outcomes following myocardial infarction (MI). The mitochondrial uncoupling protein 3 (UCP3) is down-regulated in the heart with insulin resistance. We hypothesized that decreased UCP3 levels contribute to poor cardiac recovery following ischemia/reperfusion (I/R). After confirming that myocardial UCP3 levels were systematically decreased by 20-49\% in animal models of insulin resistance and type 2 diabetes, we genetically engineered Sprague-Dawley rats with partial loss of UCP3 (ucp $3^{+/-}$). Wild-type littermates (ucp ${ }^{+/+}$) were used as controls. Isolated working hearts from $\mathrm{ucp}^{+/-}$rats were characterized by impaired recovery of cardiac power and decreased long-chain fatty acid (LCFA) oxidation following I/R. Mitochondria isolated from ucp $3^{+/-}$hearts subjected to I/R in vivo displayed increased reactive oxygen species (ROS) generation and decreased respiratory complex I activity. Supplying $\mathrm{ucp}^{+/-}$cardiac mitochondria with the medium-chain fatty acid (MCFA) octanoate slowed electron transport through the respiratory chain and reduced ROS generation. This was accompanied by improvement of cardiac LCFA oxidation and recovery of contractile function post ischemia. In conclusion, we demonstrated that normal cardiac UCP3 levels are essential to recovery of LCFA oxidation, mitochondrial respiratory capacity, and contractile function following I/R. These results reveal a potential mechanism for the poor prognosis of type 2 diabetic patients following MI and expose MCFA supplementation as a feasible metabolic intervention to improve recovery of these patients at reperfusion.
\end{abstract}

Keywords Type 2 diabetes $\cdot$ Myocardial infarction $\cdot$ Uncoupling protein $\cdot$ Cardiac metabolism $\cdot$ Mitochondrial function

Electronic supplementary material The online version of this article (https://doi.org/10.1007/s00395-018-0707-9) contains supplementary material, which is available to authorized users.

\section{Romain Harmancey}

rharmancey@umc.edu

1 Department of Physiology and Biophysics, University of Mississippi Medical Center, 2500 N. State St., Jackson, MS 39216-4505, USA

2 Mississippi Center for Obesity Research, University of Mississippi Medical Center, Jackson, MS, USA

3 Mississippi Center for Heart Research, University of Mississippi Medical Center, Jackson, MS, USA

4 Department of Medicine, University of Mississippi Medical Center, Jackson, MS, USA

5 Department of Cell and Molecular Biology, University of Mississippi Medical Center, Jackson, MS, USA

\section{Introduction}

In the United States alone, more than 35 million individuals are suffering from diabetes mellitus. By 2030, this diabetes epidemic is expected to extend to more than 54 million Americans and will lead to nearly 400,000 deaths annually [57]. Cardiovascular disease is the most prevalent cause of mortality in diabetic patients [43]. Type 2 diabetes mellitus represents $>95 \%$ of all diabetes cases [24]. The hyperinsulinemia and reduced insulin sensitivity which characterize this metabolic disorder are linked to a two- to fourfold increase in the risk for ischemic heart disease [2, 25]. Consequently, diabetic individuals represent a rapidly growing number of the patients undergoing reperfusion for acute myocardial infarction [63]. In addition to increasing the incidence of myocardial infarction (MI), diabetes is also associated with increased cardiac morbidity and mortality following revascularization $[15,19,66]$. While the pathophysiology of cardiovascular diseases in diabetes is complex 
and multifactorial, specific molecular mechanisms may underlie the poor prognosis of the diabetic patient population in response to ischemia/reperfusion (I/R).

Uncoupling protein 3 (UCP3) is a mitochondrial anion carrier protein with antioxidant properties known to stimulate long-chain fatty acid (LCFA) metabolism in muscle cells $[46,60]$. In prediabetic subjects and type 2 diabetic patients, skeletal muscle UCP3 content is decreased by almost $50 \%$ [59]. Regulation of myocardial UCP3 with hyperinsulinemia and type 2 diabetes is less clear with reports of either unchanged [12, 34], increased [51], or decreased expression $[11,32,33]$, in the rodent models explored so far. In mice, we previously demonstrated that chronic hyperinsulinemia down-regulates myocardial UCP3 content by $40 \%$ through induction of pathway-selective insulin resistance, increased recruitment of the sterol regulatory element-binding protein (SREBP)-1 transcription factor at the UCP3 promoter, and transcriptional repression of the UCP3 gene [31]. In rats rendered insulin resistant by high-sucrose feeding, we observed a similar decrease in cardiac UCP3 levels that was associated with decreased rates of myocardial LCFA oxidation after ischemia and impaired recovery of contractile function [33]. In mice, genetic deletion of UCP3 has been associated with decreased myocardial ATP content at reperfusion [53], as well as worsening of cardiac function, increased cardiomyocyte death, and greater mortality at 8 weeks post MI [55]. Based on this evidence, we hypothesized that UCP3 deficiency is responsible for impairment of myocardial LCFA oxidation at reperfusion, thereby causing energetic deficiency and impairment of contractile recovery post ischemia.

The goals of the present study were to (1) reexamine in several rodent genetic models the impact of hyperinsulinemia and type 2 diabetes on cardiac UCP 3 content, (2) investigate in a newly established, genetically modified rat model the consequences of a partial UCP3 deficiency, mimicking that seen with hyperinsulinemia and insulin resistance, on functional recovery of the heart subjected to I/R; and (3) identify the potential molecular mechanisms at play in the observed phenotype.

Our results demonstrate that myocardial UCP3 deficiency is a common feature of rodents with obesity, insulin resistance and type 2 diabetes, and is linked to the hyperinsulinemic state of the animals. Moreover, our data confirm that partial UCP3 deficiency is sufficient to impair contractile recovery of the rat heart post ischemia, which is linked to mitochondrial dysfunction and decreased capacity to oxidize LCFAs at reperfusion. We also provide evidence that this mitochondrial defect can be bypassed, at least ex vivo, by supplying the heart with a medium-chain fatty acid (MCFA). Taken together, these results support the concept that myocardial UCP3 deficiency is a mechanism for the poor prognosis of type 2 diabetic patients following MI. Our results also expose MCFA supplementation as a potential metabolic intervention to improve recovery of these patients at reperfusion.

\section{Materials and methods}

An expanded "Materials and methods" section is available in the Electronic Supplementary Material.

\section{Animals}

All animals were housed in the Center for Comparative Research animal facilities of the University of Mississippi Medical Center (UMMC). Animals were kept on a $12 \mathrm{~h}$ light/12 $\mathrm{h}$ dark cycle and fed a standard laboratory rodent diet (Teklad 8640). All procedures were conducted in accordance with the National Institutes of Health's Guide for the Care and Use of Laboratory Animals and approved by the Institutional Animal Care and Use Committee.

Male leptin-deficient $o b / o b$ mice (B6.Cg-Lep ${ }^{o b} / \mathrm{J}$ ), male leptin receptor-deficient $d b / d b$ (B6.BKS(D)-Lepr $\left.{ }^{d b} / \mathrm{J}\right)$, and male wild-type controls C57BL/6J mice were all purchased from the Jackson Laboratory. Heart tissue samples from male melanocortin 4 receptor (MC4R)-deficient mice (LoxTB MC4R $\mathrm{R}^{-/-}$), male mice with leptin receptor deletion in the entire central nervous system (LepR/Nestin-cre), and male MC4R knockout rats (MC4RKO) were obtained from animal colonies housed at UMMC. The UCP3-deficient rats were developed on a Sprague-Dawley background strain (Taconic) by Horizon Discovery using CRISPR/Cas9 technology as described in the Electronic Supplementary Material.

\section{Blood and plasma parameters}

Blood glucose levels were determined with a Contour next blood glucose monitoring system (Bayer Healthcare LLC). Plasma insulin and leptin levels were quantified using the Ultra Sensitive Mouse Insulin (Crystal Chem) and the Quantikine Mouse/Rat Leptin (R\&D Systems) ELISA kits.

\section{Immunoblotting}

Details on the immunoblotting procedures and antibodies used can be found in the Electronic Supplementary Material.

\section{Echocardiography}

Cardiac structure and function were assessed by high-frequency echocardiography using a Vevo 3100 imaging system (VisualSonics). Rats were sedated using 2\% isoflurane gas and placed on a prewarmed pad with continuous electrocardiographic monitoring. Each echocardiographic session 
was performed in less than 10 min to minimize the cardiac effects of anesthesia. Two-dimensional B-mode images were obtained from the parasternal long and short axis views. M-Mode images were obtained at the midpapillary muscle level from the short axis view. The Vevo Lab 3.1.1 software cardiac package was used to determine left ventricular (LV) wall dimensions and volume at end-diastole and end-systole, fractional shortening (\%), stroke volume, and ejection fraction $(\%)$ from an average of five cardiac cycles.

\section{Working heart preparation}

Fifty-one to 61-week-old rats were anesthetized with inhaled isoflurane (3\%) and intravenously injected with 200 USP units heparin prior to heart removal. Perfusions were carried out on spontaneously beating hearts following previously established protocols [6]. Detailed descriptions on perfusion conditions and data acquisition are provided in the Electronic Supplementary Material.

\section{Working heart perfusion protocol}

Global myocardial ischemia was induced ex vivo according to the guidelines for experimental models of myocardial ischemia and infarction [44]. Hearts were perfused for 20 min under baseline conditions, after which total, global, normothermic ischemia was induced by clamping both the aortic and the atrial lines on the perfusion system. After $15 \mathrm{~min}$ no-flow ischemia, hearts were reperfused for $30 \mathrm{~min}$ by unclamping both lines. Measurement of cardiac parameters was reinitiated at $5 \mathrm{~min}$ into reperfusion, or at the time point following the recovery of aortic pressure, whichever came first. At the end of the protocol, hearts were freezeclamped with aluminum tongs cooled in liquid nitrogen and stored at $-80{ }^{\circ} \mathrm{C}$.

\section{In vivo myocardial infarction and reperfusion}

14- to 22-week-old rats were anesthetized by intraperitoneal injection of a mixture of ketamine $(100 \mathrm{mg} / \mathrm{kg})$ and xylazine $(10 \mathrm{mg} / \mathrm{kg})$. Correct depth of anesthesia was ascertained by lack of toe pinch and palpebral reflexes. Rats were then intubated with a $16 \mathrm{G}$ catheter connected to a small animal ventilator (Harvard Apparatus). A small skin cut was made over the left chest. After dissection of the pectoral major and minor muscles, the fourth intercostal space was exposed. A small window was made at the fourth intercostal space to open the pleural membrane and pericardium. Myocardial infarction was induced by ligation of the left anterior descending artery (LAD) using a 4-0 nylon suture tied over a small polyethylene tube. After 45 min ischemia, the tube was removed to allow reperfusion. After 15 min reperfusion, the heart was quickly excised from the chest and placed into ice-cold MSM buffer (220 mM mannitol, $70 \mathrm{mM}$ sucrose, $5 \mathrm{mM}$ MOPS $\mathrm{pH}$ 7.4). Following aortic cannulation and retying of the LAD with the suture, the heart was retrogradely perfused with ice-cold MSM to wash blood away. Ice-cold saline supplemented with $0.01 \%$ Evans blue was subsequently injected to identify the LV remote and infarct areas. Prior analyses demonstrated that tissue perfusion with $0.01 \%$ Evans blue had no effect on mitochondrial function per se.

\section{Mitochondrial isolation}

Heart mitochondria were isolated following previously established protocols with minor modifications [62]. In brief, cardiac tissue was minced with a razor blade in icecold MSM buffer supplemented with $1 \mathrm{mg} / \mathrm{ml}$ bacterial proteinase type XXIV (Nagarse). The minced tissue was added to 8-10 $\mathrm{ml}$ ice-cold isolation buffer (MSM buffer supplemented with $2 \mathrm{mM}$ EDTA and $0.2 \%$ fatty acid-free BSA) and homogenized on ice with a glass homogenizer and a Teflon pestle. To minimize damage to the mitochondria, the homogenate was poured off after $\sim 5$ strokes. After addition of $0.1 \mathrm{mM}$ phenylmethylsulfonyl fluoride (PMSF), the homogenate was centrifuged at $300 \times g$ for $10 \mathrm{~min}$ at $4{ }^{\circ} \mathrm{C}$. The supernatant was then centrifuged at $3000 \times g$ for $10 \mathrm{~min}$ at $4{ }^{\circ} \mathrm{C}$, and the mitochondrial pellet washed once in ice-cold isolation buffer. After final resuspension in ice-cold isolation buffer, mitochondrial protein concentration was determined using the DC Protein assay (Bio-Rad). Citrate synthase activity was nine times higher in the mitochondrial fraction when compared to the cytosolic fraction, thereby confirming minimal disruption of mitochondria during the isolation procedure. Methods used for the determination of mitochondrial function and the assessment of respiratory complex activities are provided in the Electronic Supplementary Material.

\section{Transmission electron microscopy}

Left ventricular tissue samples $\left(\sim 1 \mathrm{~mm}^{3}\right)$ were quickly dissected following euthanasia and immediately fixed in glutaraldehyde. After thin sectioning (70 nm in thickness) and application on copper grids, the stained samples were loaded in a JOEL JEM-1400Plus transmission electron microscope for data acquisition. At least five sections from each sample were examined under transmission electron microscopy. The entire sections were thoroughly viewed at low magnification $(300 \times)$ for integrity and quality of stained tissues. Mitochondrial ultrastructure was further investigated at high magnifications. 


\section{Isolation and culture of adult rat ventricular myocytes}

Adult rat ventricular myocytes (ARVM) were isolated according to a modified version of the method developed by Ackers-Johnson and colleagues [3]. In brief, rats anesthetized with inhaled isoflurane (3\%) were intravenously injected with 200 USP units heparin and their hearts subsequently removed and immediately transferred into ice-cold EDTA buffer. Following aortic cannulation, the hearts were retrogradely perfused first with $20 \mathrm{ml}$ of ice-cold EDTA buffer to wash them free of blood, then with $40 \mathrm{ml}$ of icecold perfusion buffer, and last with $40 \mathrm{ml}$ of recirculating collagenase buffer pre-warmed at $38{ }^{\circ} \mathrm{C}$. After proceeding with mechanical dissociation of heart tissue, cell separation by gravity settlement, and calcium re-introduction, ARVM were plated in 24-well culture plates on laminincoated coverslips. After $24 \mathrm{~h}$ in culture, ARVM were subjected to anoxia/reperfusion using the method of enzymatically generated oxygen deficiency [8]. Oxygen depletion was initiated by replacing the culture media with medium containing glucose oxidase $(2 \mathrm{U} / \mathrm{ml})$ and catalase $(120 \mathrm{U} /$ $\mathrm{ml})$. After $30 \mathrm{~min}$ incubation, ARVM were washed three times with fresh culture medium and incubated for another $30 \mathrm{~min}$ in culture medium containing $0.5 \mathrm{mM}$ MitoSOX Red (Molecular Probes). At the end of the incubation period, cells were washed three times with PBS and fixed for $10 \mathrm{~min}$ in $4 \%$ paraformaldehyde solution. The coverslips were then mounted on microscope slides with VECTASHIELD Antifade Mounting Medium with DAPI (Vector Laboratories) and analyzed with an epifluorescence microscope at the manufacturers' recommended wavelengths.

\section{Cardiac enzyme activity and malonyl-CoA levels}

Activity of the antioxidant enzymes glutathione peroxidase (GPx), catalase (CAT), and superoxide dismutase (SOD) was determined using colorimetric assay kits (Cayman Chemical) following the manufacturer's protocols. Cardiac tissue malonyl-CoA levels were determined using a rat malonyl coenzyme A ELISA kit (Biomatik). Carnitine palmitoyl transferase (CPT) activity was determined using the isotope forward assay as detailed in the Electronic Supplementary Material.

\section{Statistical analyses}

Data are expressed as mean \pm SE. In consideration of sex as a biological variable, UCP3-deficient rats of both sexes were included in the study. In initial experiments involving ex vivo working heart perfusions and isolated mitochondria, all normalized parameters were found to be similar in both sexes and were consequently pooled together for final analyses. Comparisons between two groups were performed using paired or unpaired Student $t$ test. Comparisons between multiple experimental groups were made by oneway analysis of variance with Tukey's post hoc test. A $p$ value $<0.05$ was considered statistically significant. All the analyses were performed with GraphPad Prism version 7.

\section{Results}

\section{Cardiac UCP3 content is decreased in monogenic mouse and rat models of obesity, insulin resistance and type 2 diabetes}

Because of the conflicting reports on the effect of non-insulin-dependent diabetes on UCP3 expression in the heart, we first set out to quantify cardiac UCP3 levels in a panel of rodent models of obesity, insulin resistance and type 2 diabetes. We used a recently developed monoclonal antibody that recognizes both UCP1 and UCP3. Specificity for UCP3 was validated on tissue protein lysates from UCP3 knockout rats (Supplemental Fig. 1c). Cardiac UCP3 content was decreased by $20 \%$ in two of the most widely used models of obesity and type 2 diabetes, the $o b / o b$ and $d b / d b$ mice (Fig. 1a, g). As expected, although both $o b / o b$ and $d b / d b$ mice displayed severe hyperglycemia and hyperinsulinemia (Fig. 1b, c), only $d b / d b$ mice developed hyperleptinemia, while circulating leptin levels were below detection range for $o b / o b$ mice (Fig. 1d). An even stronger decrease in cardiac $\mathrm{UCP} 3$ content was observed in the LoxTB MC4R ${ }^{-1-}$ mice (28-34\% decrease) and LepR/Nestin-cre mice (38-40\% decrease; Fig. 1e, g), two other models of type 2 diabetes which are also characterized by severe obesity, insulin resistance, hyperinsulinemia, and glucose intolerance [7, 49]. A strong 36-49\% decrease in cardiac UCP3 content was also observed in the MC4RKO rat (Fig. 1f, g), a rodent model with marked obesity, insulin resistance, and hyperinsulinemia [65]. Thus, cardiac UCP3 content is consistently decreased in obese, insulin-resistant, and type 2 diabetic animals, and a common denominator to this decrease is the development of hyperinsulinemia mediated by insulin resistance.

\section{Partial loss of UCP3 impairs LCFA oxidation and contractile recovery in rat hearts post ischemia}

To recapitulate the decrease in UCP3 levels caused by hyperinsulinemia, insulin resistance and type 2 diabetes, CRISPRCas9 genome editing was used to inactivate one copy of the UCP3 gene in Sprague-Dawley rats $\left(\mathrm{ucp}^{+/-}\right)$. Mutant male and female adult rats had normal cardiac functional and structural parameters when compared to their wild-type ucp $3^{+/+}$ counterparts (Supplemental Table 1). Isolated working hearts 

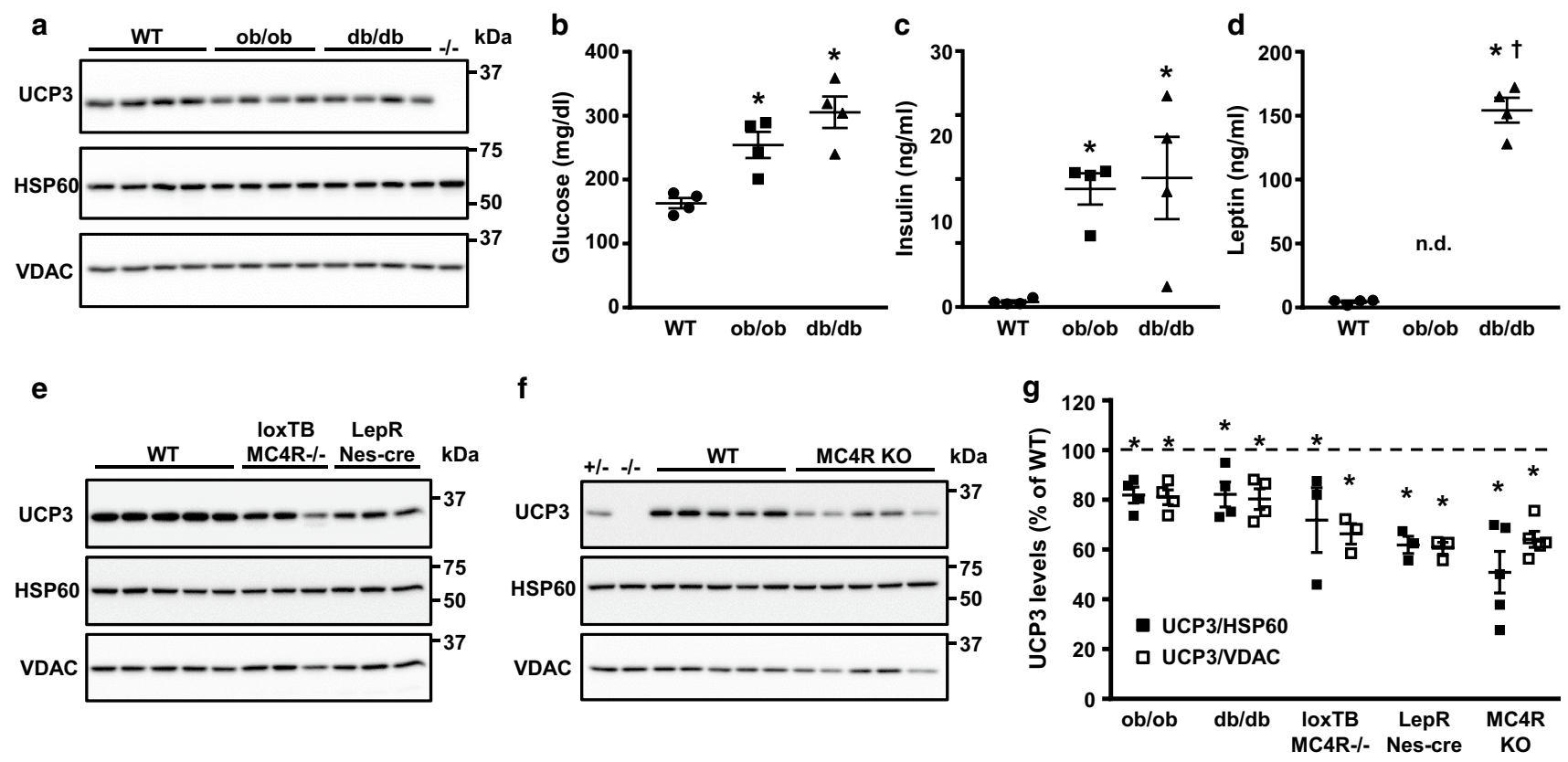

Fig. 1 Cardiac UCP3 levels are decreased in rodent models of obesity, insulin resistance and type 2 diabetes. a Immunoblotting revealed a decrease in UCP3 protein levels in hearts of male $o b / o b$ mice $(n=4)$ and male $d b / d b$ mice $(n=4)$ when compared to wild-type (WT) male C57BL/6J control mice $(n=4)$. Both ob/ob and $d b / d b$ mice were hyperglycemic (b) and hyperinsulinemic (c). d $d b / d b$ mice displayed severe hyperleptinemia, while plasma leptin levels were undetectable in $o b / o b$ mice. e UCP3 protein levels were also decreased in hearts from type 2 diabetic male LoxTB MC4R ${ }^{-/-}$mice

from both groups of animals also displayed similar functional and metabolic parameters when perfused under baseline conditions with oleate as the exogenous source of fatty acids for $\beta$-oxidation (Fig. 2; Table 1). But while cardiac power from ucp $3^{+/+}$hearts recovered to near-baseline values following 15 min of total global normothermic ischemia, hearts from $\mathrm{ucp}^{+/-}$animals experienced a rapid and sustained impairment in contractile function at reperfusion (Fig. 2a). Time to recovery of aortic pressure post ischemia also tended to increase for the ucp $3^{+/-}$hearts ( $p=0.08$; Fig. 2b). Myocardial rates of glucose oxidation increased transiently at early reperfusion for both groups and then declined to pre-ischemia rates during late reperfusion (Fig. 2c). However, rates of long-chain fatty acid oxidation decreased significantly in ucp $3^{+/-}$hearts during the late reperfusion period, as compared to the pre-ischemia rates (Fig. 2d). As an apparent consequence, both $\mathrm{M} V_{O_{2}}$ and cardiac efficiency dropped significantly for ucp $3^{+/-}$hearts during reperfusion (Fig. 2e, f).

\section{Partial loss of UCP3 impairs mitochondrial LCFA oxidation in rat hearts post ischemia}

In order to determine whether an impairment of LCFA oxidation in ucp $3^{+/-}$hearts may also occur in vivo in response to $(n=3)$ and male LepR/Nestin-cre mice $(n=3)$. f Cardiac UCP3 protein levels were similarly decreased in hearts from obese and insulin-resistant MC4RKO rats $(n=5)$. $\mathbf{g}$ The decrease in cardiac UCP3 protein levels in these animals ranged between 20 and 49\%. Similar results were obtained when normalizing UCP3 levels to the ubiquitous cellular protein HSP60 or to the mitochondrial protein VDAC. Data are presented as mean \pm SE. ${ }^{*} p<0.05$ vs. WT animals; ${ }^{\dagger} p<0.05$ vs. $o b / o b$ mice

$\mathrm{I} / \mathrm{R}$, male and female rats were subjected to $45 \mathrm{~min}$ of acute MI followed by $15 \mathrm{~min}$ of reperfusion. Electron microscopy visualization of LV cardiac tissue from the remote area did not reveal any difference in cardiomyocyte ultrastructure among genotypes. However, in the infarct area, the number and size of cytosolic lipid droplets increased noticeably in cardiomyocytes from ucp $3^{+/-}$animals (Fig. 3a).

Carnitine palmitoyltransferase I (CPT1), the enzyme controlling the transport of LCFAs in the mitochondrial matrix, is regarded as the rate-limiting enzyme in fatty acid $\beta$-oxidation [26]. The activity of CPT1 in the heart is highly regulated and can be strongly inhibited by compounds and metabolites such as malonyl-CoA (Fig. 3b). However, the activity of CPT1 and malonyl-CoA content of ucp $3^{+/-}$hearts subjected to I/R were similar to that of $\mathrm{ucp}^{+/+}$hearts (Fig. 3c, d), suggesting that the impairment of LCFA oxidation occurs downstream of their mitochondrial import.

To further investigate whether the impairment of LCFA oxidation in ucp $3^{+/-}$hearts is linked to a mitochondrial defect occurring at reperfusion, mitochondria were isolated from LV cardiac tissue after MI/reperfusion and their respiratory capacity in presence of various substrates compared. In mitochondria isolated from the remote area of both groups, the rate of ADP-stimulated respiration of oleate was 
a
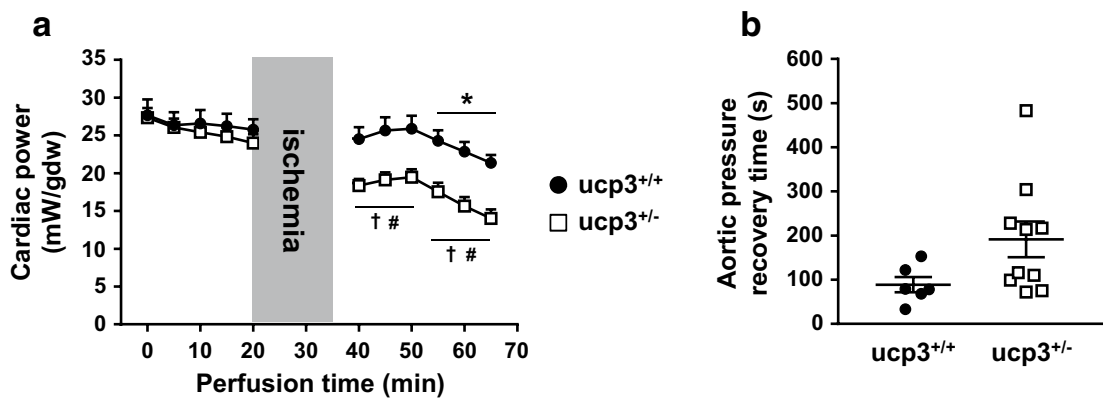

d

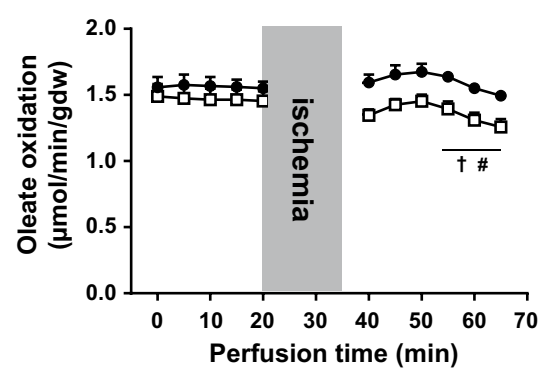

e

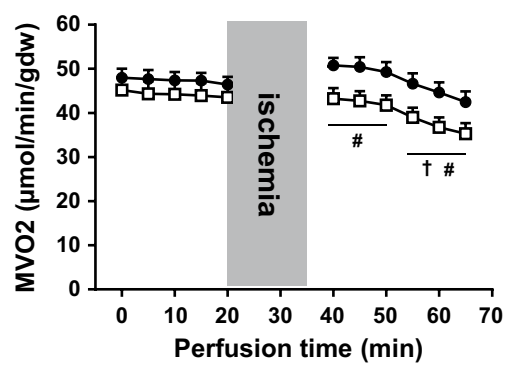

C

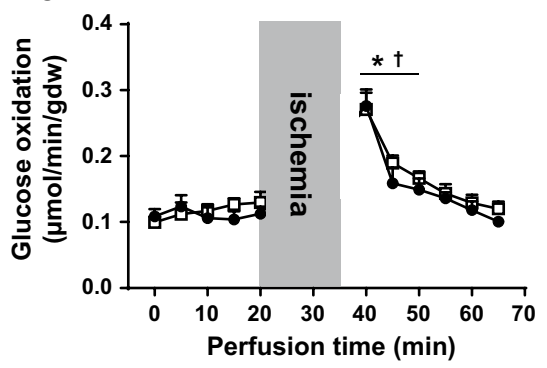

f

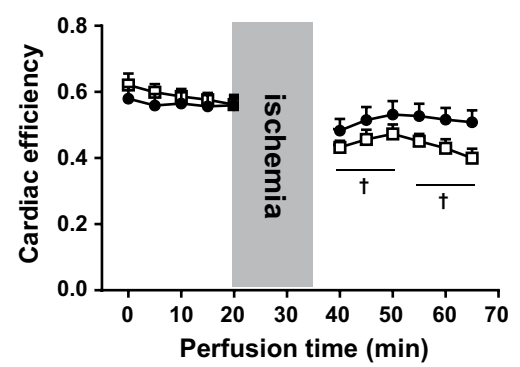

Fig. 2 Partial loss of UCP3 impairs metabolic and functional recovery of rat hearts at reperfusion. Isolated hearts from $u c p 3^{+/+}$control rats (black circles, $n=6-8$ ) and $\mathrm{ucp} 3^{+/-}$rats (open squares, $n=10-11$ ) were perfused in the working mode in the presence of $5.5 \mathrm{mM}$ glucose and $0.8 \mathrm{mM}$ of the LCFA oleate as substrates. Cardiac power (a), time to recovery of aortic pressure post ischemia (b), rates of glucose oxidation (c), rates of oleate oxidation (d), myocardial oxygen consumption (e), and cardiac efficiency (f) were determined as described in the "Methods" section. Data are presented as

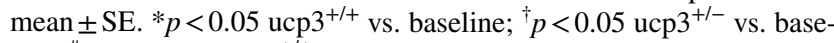
line. ${ }^{\#} p<0.05$ vs. ucp $3^{+/+}$

Table 1 Functional and metabolic parameters of isolated working hearts

\begin{tabular}{|c|c|c|c|c|c|c|c|c|c|c|}
\hline \multirow[t]{2}{*}{ Ucp3 } & & \multicolumn{3}{|c|}{ Baseline (0-20 min) } & \multicolumn{3}{|c|}{ Early reperfusion (35-50 min) } & \multicolumn{3}{|c|}{ Late reperfusion (50-65 min) } \\
\hline & & $\mathrm{OL}$ & OA & OL/OA & OL & $\mathrm{OA}$ & $\mathrm{OL} / \mathrm{OA}$ & OL & OA & OL/OA \\
\hline \multirow[t]{5}{*}{$+/+$} & $\mathrm{CP}$ & $26.5 \pm 0.7$ & $25.3 \pm 0.6$ & $26.6 \pm 0.9$ & $25.3 \pm 0.9$ & $22.8 \pm 1.1$ & $23.0 \pm 1.3$ & $22.8 \pm 0.7 *$ & $24.6 \pm 1.1$ & $22.6 \pm 1.2$ \\
\hline & GO & $111 \pm 6$ & $80 \pm 7^{\dagger}$ & $85 \pm 5^{\dagger}$ & $195 \pm 18^{*}$ & $115 \pm 10^{\dagger}$ & $148 \pm 13^{*}$ & $118 \pm 7$ & $91 \pm 8^{\dagger}$ & $102 \pm 10$ \\
\hline & $\mathrm{FAO}^{\mathrm{a}}$ & $1563 \pm 29$ & $4853 \pm 190$ & $348 \pm 22^{\dagger}$ & $1641 \pm 36$ & $4562 \pm 212$ & $502 \pm 43^{*}, \dagger$ & $1561 \pm 23$ & $4762 \pm 149$ & $514 \pm 33^{*, \dagger}$ \\
\hline & $\mathrm{M} V_{O 2}$ & $47.3 \pm 0.8$ & $44.8 \pm 0.8$ & $42.8 \pm 1.7^{\dagger}$ & $50.1 \pm 1.1$ & $45.2 \pm 0.9$ & $46.8 \pm 2.3$ & $44.6 \pm 1.3$ & $41.1 \pm 1.3$ & $43.2 \pm 2.0$ \\
\hline & $\mathrm{CE}$ & $0.56 \pm 0.01$ & $0.57 \pm 0.02^{\#}$ & $0.63 \pm 0.02^{\dagger}$ & $0.51 \pm 0.02$ & $0.51 \pm 0.02$ & $0.50 \pm 0.02 *$ & $0.52 \pm 0.02$ & $0.60 \pm 0.03^{\dagger}$ & $0.53 \pm 0.03 *$ \\
\hline \multirow[t]{5}{*}{$+/-$} & $\mathrm{CP}$ & $25.5 \pm 0.5$ & $24.1 \pm 0.6$ & $25.0 \pm 0.7$ & $19.0 \pm 0.6^{*}$ & $21.3 \pm 0.8^{\#}$ & $23.9 \pm 0.7^{\dagger}$ & $15.7 \pm 0.7 *$ & $22.2 \pm 0.7^{\dagger}$ & $21.7 \pm 0.8^{\dagger}$ \\
\hline & GO & $117 \pm 6$ & $78 \pm 4^{\dagger, \#}$ & $113 \pm 7$ & $207 \pm 12 *$ & $132 \pm 8^{*, \dagger}$ & $160 \pm 9 *, \dagger$ & $131 \pm 7$ & $88 \pm 6^{\dagger}$ & $106 \pm 7^{\dagger}$ \\
\hline & $\mathrm{FAO}^{\mathrm{a}}$ & $1470 \pm 36$ & $5080 \pm 80$ & $397 \pm 9^{\dagger}$ & $1410 \pm 28$ & $4818 \pm 126$ & $554 \pm 24^{*, \dagger}$ & $1320 \pm 34^{*}$ & $4888 \pm 107$ & $540 \pm 20^{*, \dagger}$ \\
\hline & $\mathrm{M} V_{O 2}$ & $44.2 \pm 1.2$ & $43.6 \pm 1.0^{\#}$ & $48.5 \pm 0.6^{\dagger}$ & $42.5 \pm 1.3$ & $45.0 \pm 1.4^{\#}$ & $49.9 \pm 0.7^{\dagger}$ & $37.0 \pm 1.3^{*}$ & $41.2 \pm 1.1^{\dagger, \#}$ & $45.2 \pm 0.7^{\dagger}$ \\
\hline & $\mathrm{CE}$ & $0.59 \pm 0.01$ & $0.56 \pm 0.01$ & $0.51 \pm 0.02^{\dagger}$ & $0.45 \pm 0.02 *$ & $0.48 \pm 0.02 *$ & $0.48 \pm 0.02$ & $0.43 \pm 0.02 *$ & $0.55 \pm 0.02^{\dagger, \#}$ & $0.48 \pm 0.02$ \\
\hline
\end{tabular}

Hearts were subjected to I/R and perfused with the LCFA oleate (OL), the MCFA octanoate (OA), or an equimolar mixture of both fatty acids $(\mathrm{OL} / \mathrm{OA})$ as described in the "Materials and methods" section. Data are presented as mean $\pm \mathrm{SE}$

$C E$ cardiac efficiency, $C P$ cardiac power (mW/gdw), $G O$ glucose oxidation (nmol $/ \mathrm{min} / \mathrm{gdw}), F A O$ fatty acid oxidation (nmol/min/gdw), $M V_{O 2}$ myocardial oxygen consumption $(\mu \mathrm{mol} / \mathrm{min} / \mathrm{gdw})$

${ }^{*} p<0.05$ vs. baseline; ${ }^{\dagger} p<0.05$ vs. OL; ${ }^{\#} p<0.05$ vs. OL/OA

${ }^{\text {a }}$ Only rates of oleate oxidation were measured in the OL/OA condition

similar (Fig. 4a). In mitochondria isolated from the infarct area of $\mathrm{ucp}^{+/+}$hearts, the rate of ADP-stimulated respiration of oleate was the same as remote levels, but the rate decreased by $16 \%$ in the ucp $3^{+/}$group (Fig. 4a). A similar decrease was observed for ADP-stimulated respiration of glutamate/malate by ucp $3^{+/-}$mitochondria isolated from the infarct area (Fig. 4b, c). However, such a decrease was not observed when using the complex II substrate succinate, 
Fig. 3 UCP3 deficiency induces cytosolic lipid accumulation in cardiomyocytes following I/R. a Electron micrographs of cardiac tissue from rat hearts subjected to in vivo MI/reperfusion. The ultrastructure of cardiomyocytes from the remote (control) and the infarct (I/R) areas is presented. Red arrows indicate lipid droplets. Representative photomicrographs of $n=3$ rats per group and per condition are shown. b The inhibition of myocardial CPT1 activity by incubation of heart tissue lysates $(n=4)$ with the known CPT1 inhibitors etomoxir $(100 \mu \mathrm{M})$ and malonyl-CoA $(200 \mu \mathrm{M})$ confirmed the specificity of the assay. CPT1 activity (c) and malonyl-CoA levels

(d) were determined in hearts from ucp $3^{+/+}$control rats (black circles, $n=8)$ and ucp $3^{+/-}$rats (open squares, $n=10$ ) following I/R. Data are presented as mean \pm SE. $* p<0.05$

\section{a} ucp $^{+/+}$
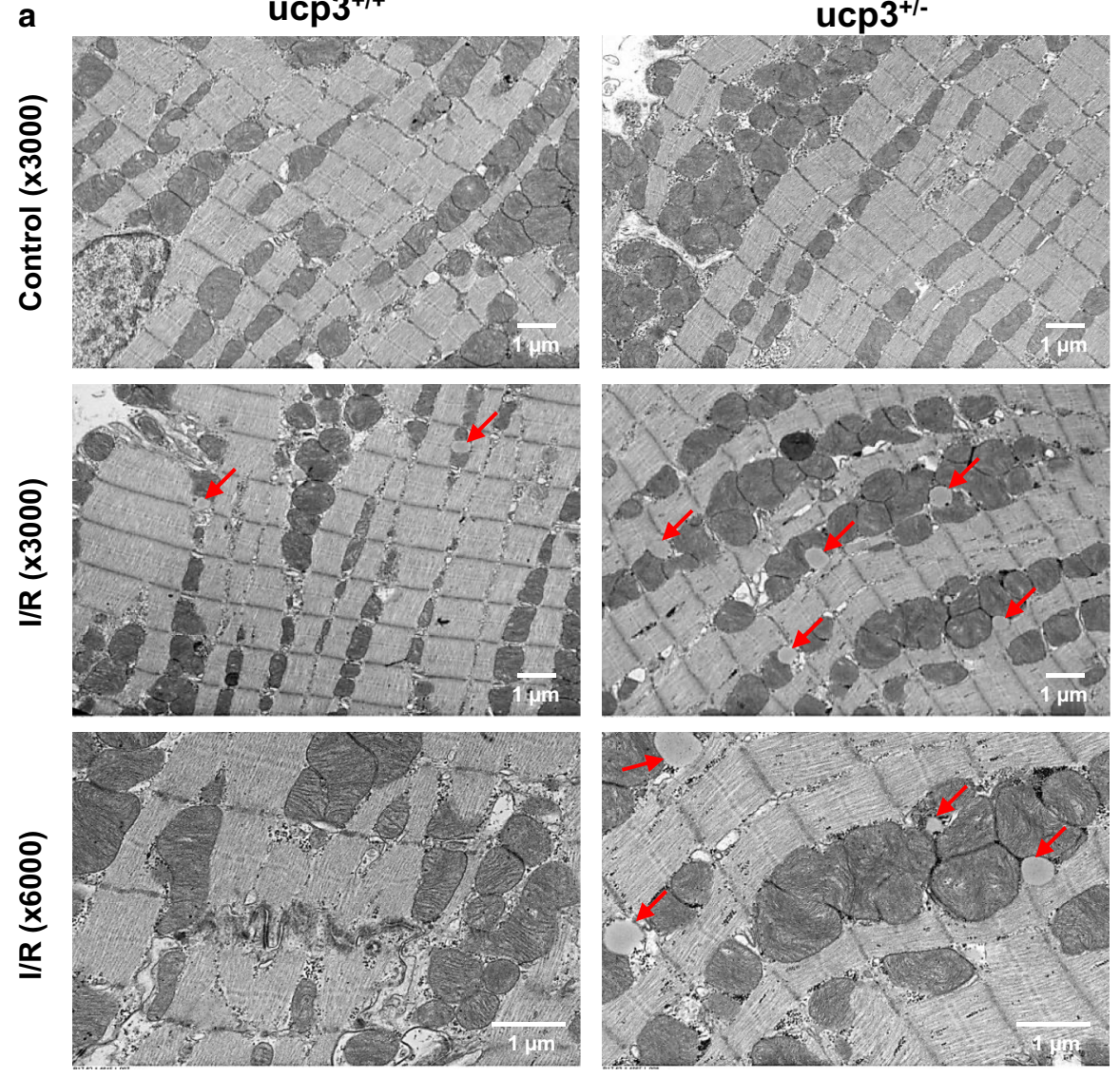

b

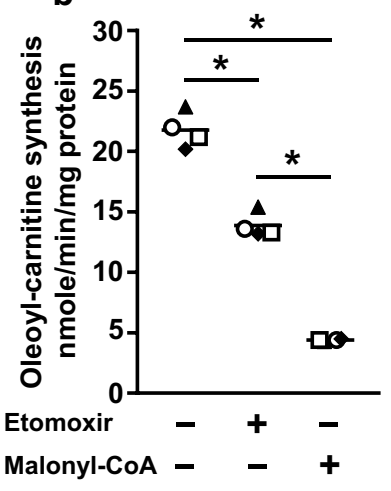

C

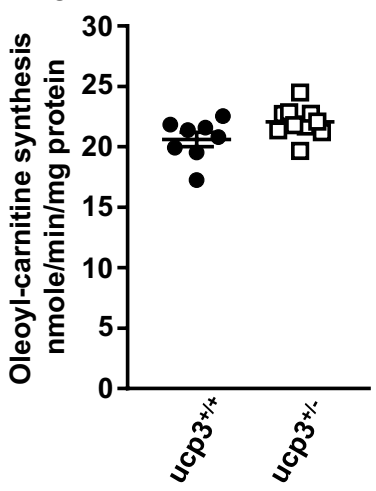

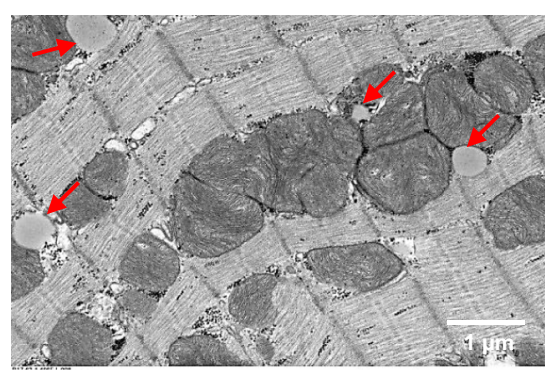

d

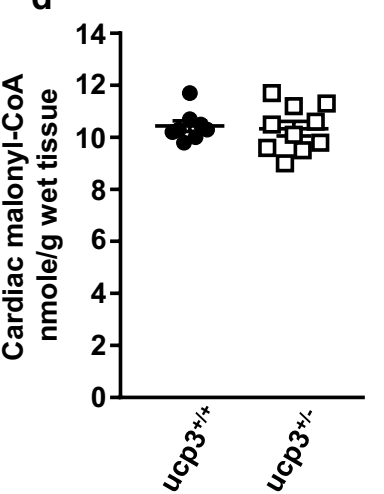

although ADP-stimulated respiration was overall slower in this condition (Fig. 4d). Consistent with the respiratory substrate analyses, complex I activity, but not complex III activity, was decreased in ucp $3^{+/-}$mitochondria subjected to I/R (Fig. 4e, f). Complex IV activity (data not shown) remained unaltered for both genotypes before and after ischemia.

\section{Mitochondrial ROS production increases in UCP3-deficient hearts post ischemia}

Mitochondrial reactive oxygen species (ROS) production has previously been reported to increase in hearts of ucp $^{-1-}$ mice and to mediate cardiac injury following MI $[53,55]$. In order to determine whether ROS generation is similarly exacerbated by partial UCP3 deficiency in rat cardiomyocytes in response to acute hypoxic stress, ARVM were subjected to $30 \mathrm{~min}$ anoxia followed by 30 min reoxygenation in the presence of the mitochondrial superoxide probe MitoSOX. Compared to cells maintained under normoxic conditions, superoxide generation increased on average by $41 \%$ in ucp $3^{+/+}$cardiomyocytes subjected to anoxia-reoxygenation. Cells with decreased amounts of UCP3 amplified ROS generation 

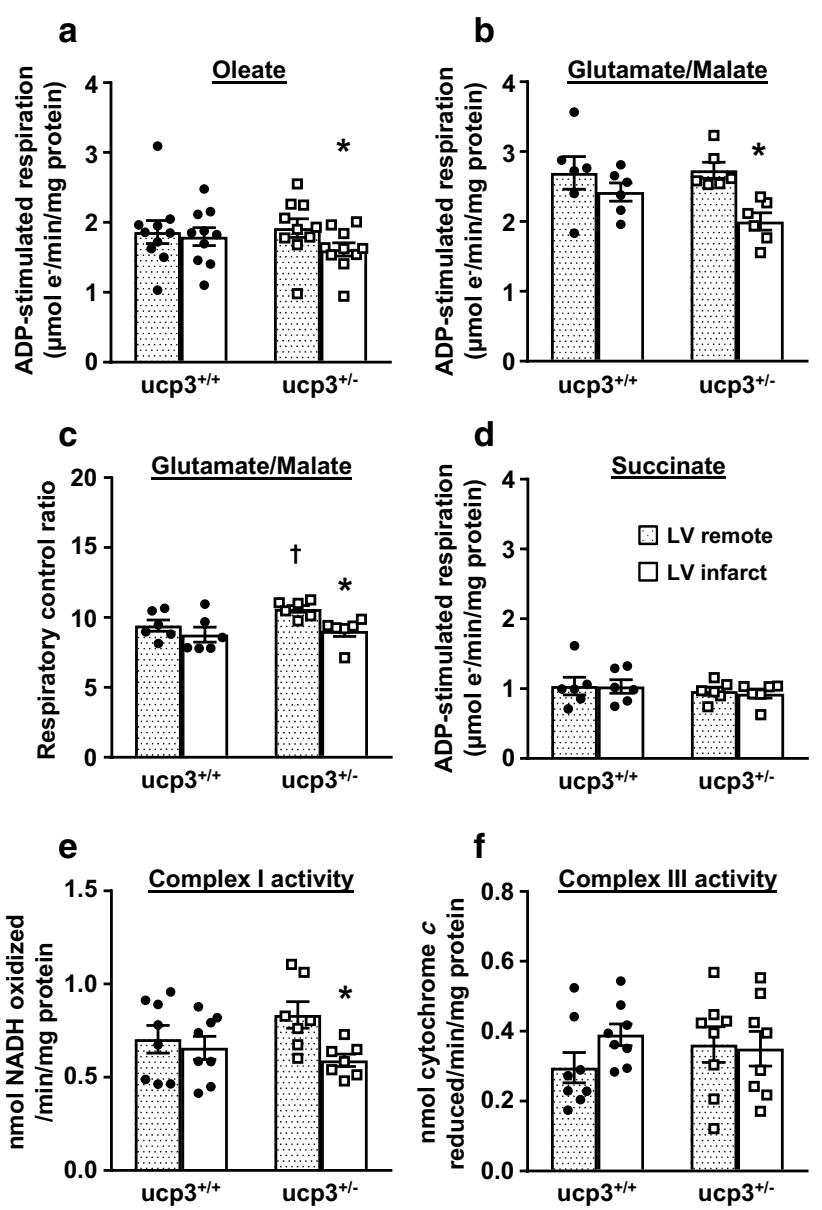

Fig. 4 Partial loss of UCP3 impairs mitochondrial function post ischemia. Hearts from ucp $3^{+/+}$control rats (black circles, $n=6-10$ ) and $\mathrm{ucp} 3^{+/-}$rats (open squares, $n=6-10$ ) were subjected to MI/reperfusion. Mitochondrial function from the remote region (dotted bars) and the infarct area (open bars) were then analyzed in parallel to determine the rates of ADP-stimulated respiration in the presence of $0.5 \mathrm{mM}$ oleate (a), the rates of ADP-stimulated respiration in the presence of $20 \mathrm{mM}$ glutamate and $10 \mathrm{mM}$ malate (b), the respiratory control ratio in the presence of $20 \mathrm{mM}$ glutamate and $10 \mathrm{mM}$ malate (c), and the rates of ADP-stimulated respiration in the presence of $20 \mathrm{mM}$ succinate (d). The activity of the respiratory complex I (e) and complex III (f) was determined using broken mitochondria prepared as described in the "Methods" section. Data are presented as mean \pm SE. $* p<0.05$ vs. LV remote. ${ }^{\dagger} p<0.05$ vs. ucp $3^{+/+}$

at reperfusion, with superoxide levels increasing by $67 \%$ on average (Fig. 5a). An increase in ROS generation was also observed in UCP3-deficient mitochondria isolated from $L V$ cardiac tissue subjected to $\mathrm{I} / \mathrm{R}$ when using oleate as the respiratory substrate (Fig. 5b). This increase in mitochondrial ROS generation was not accompanied by a compensatory increase of cellular antioxidant defenses in UCP3-deficient hearts as the activity of CAT, SOD, and GPx remained unchanged when compared to cardiac tissue from ucp $3^{+/+}$rats (Fig. 5c-e).

\section{Hearts from UCP3-deficient rats supplied with octanoate are protected from mitochondrial and contractile dysfunction at reperfusion}

The I/R protocol was repeated on isolated working hearts from both genotypes, this time replacing oleate by the MCFA octanoate as the exogenous source of fatty acids for $\beta$-oxidation (Fig. 6a-f). Under baseline conditions, ucp $3^{+/+}$ hearts perfused with octanoate had similar cardiac power as when perfused with oleate (Table 1). Following ischemia, the contractile function of ucp $3^{+/+}$hearts perfused with octanoate recovered completely (Fig. 6a) although the time to recovery of aortic pressure (Fig. 6b) tended to increase in comparison to hearts perfused with oleate $(249 \pm 90$ vs. $89 \pm 17 \mathrm{~s} ; p=0.08$ ). Octanoate was readily oxidized by the ucp $^{+/+}$hearts before and after ischemia (Fig. 6d). In comparison to oleate, perfusion with octanoate led to a $28 \%$ decrease in myocardial rates of glucose oxidation at baseline, as well as $41 \%$ and $23 \%$ decreases during the early and late reperfusion periods, respectively (Table 1).

All cardiac parameters for ucp $3^{+/-}$hearts perfused with octanoate evolved comparably to those of ucp $3^{+/+}$hearts perfused with octanoate (Fig. 6a-f). Cardiac power, $\mathrm{M} V_{O 2}$, and cardiac efficiency of ucp $3^{+/-}$hearts perfused with octanoate were all improved in late reperfusion period when compared to ucp $3^{+/-}$hearts reperfused with oleate (Table 1 ). This improvement occurred in spite of a time to recovery of aortic pressure similar to the one observed on perfusion with oleate $(254 \pm 43$ vs. $192 \pm 41 \mathrm{~s} ; p=0.31)$.

In mitochondria isolated from ucp $3^{+/+}$hearts, the MCFA octanoate tended to decrease ADP-stimulated respiration rates when compared to the LCFA oleate $(1.45 \pm 0.12$ vs. $1.86 \pm 0.16 \mu \mathrm{mol} \mathrm{e}^{-} / \mathrm{min} / \mathrm{mg}$ protein; $\left.p=0.06\right)$. This had, however, no detrimental effect on mitochondrial energization since the mitochondrial membrane potential was comparable to the one obtained with oleate (Fig. $6 \mathrm{~g}$ ). In further contrast to oleate, the ADP-stimulated respiration rate of $\mathrm{ucp}^{+/-}$cardiac mitochondria oxidizing octanoate was preserved following MI-reperfusion (Fig. 6h). Although mitochondrial ROS generation during octanoate oxidation was still amplified by UCP3 deficiency at reperfusion, the increase in ROS was 13\% lower than that observed in the comparable experiment using oleate as the respiratory substrate (Fig. 6i).

\section{Octanoate supplementation preserves mitochondrial oleate oxidation and contractile recovery of UCP3-deficient rat hearts at reperfusion}

Similar to the use of octanoate alone, the reperfusion of ucp $^{+/+}$hearts with a mixture of $50 \%$ octanoate and $50 \%$ oleate maintained cardiac power under basal conditions (Table 1). Utilization of the octanoate/oleate mixture 

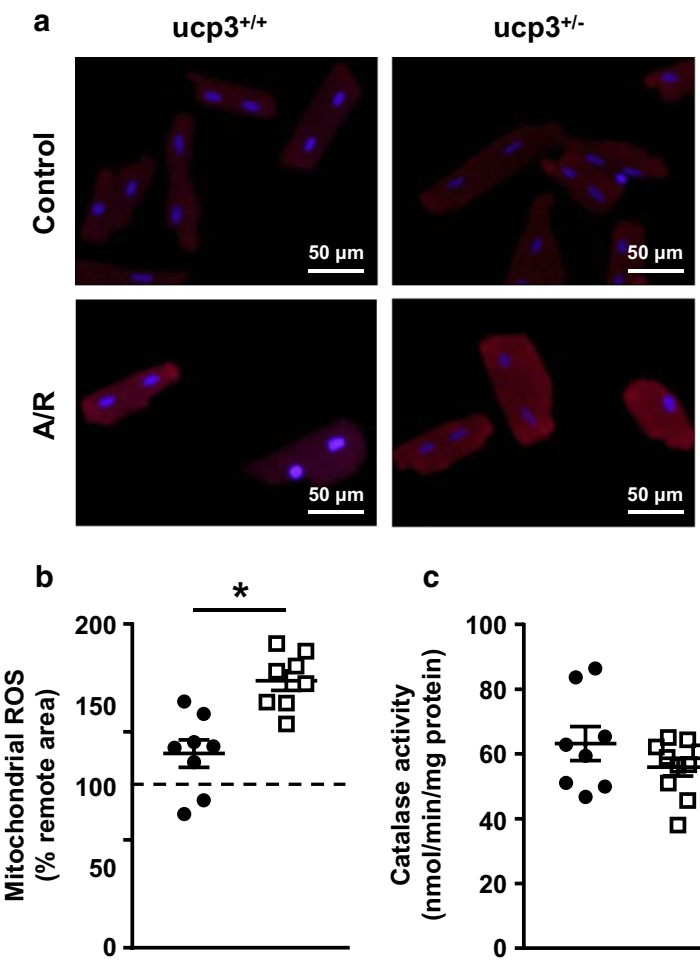

c

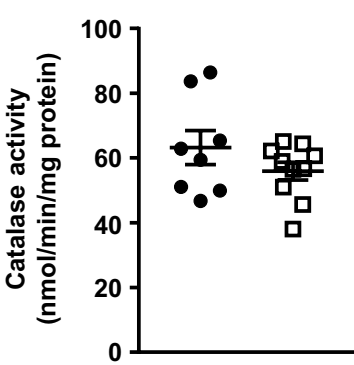

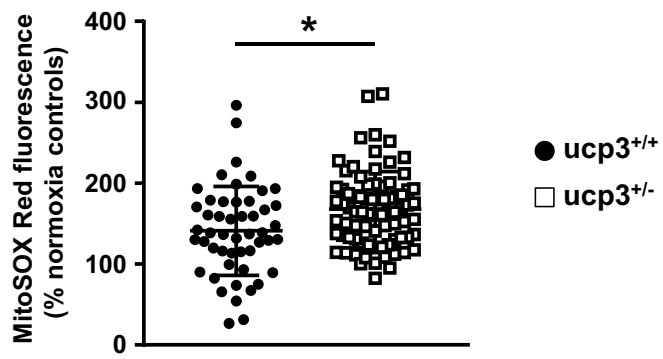

d

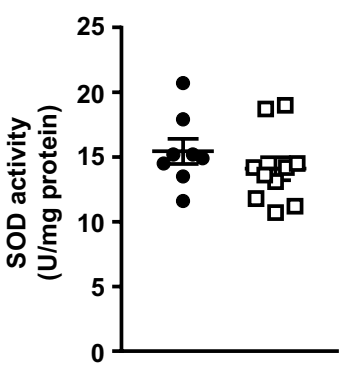

e

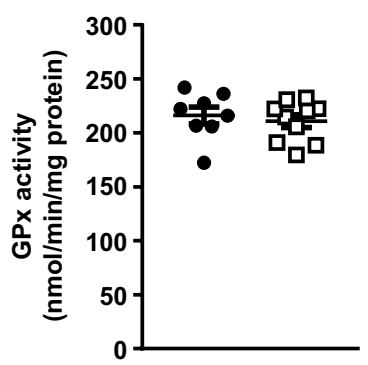

Fig. 5 Partial loss of UCP3 increases mitochondrial ROS production post ischemia. a Cultured adult rat ventricular myocytes isolated from ucp $3^{+/+}$(black circles, $n=50$ ) and ucp $3^{+/-}$(open squares, $n=79$ ) rats were exposed to $30 \mathrm{~min}$ anoxia followed by $30 \mathrm{~min}$ reoxygenation $(\mathrm{A} / \mathrm{R})$ in the presence of the superoxide probe MitoSOX Red. b Cardiac mitochondria were isolated from the remote regions and the infarct areas of ucp $3^{+/+}$(black circles, $n=8$ ) and ucp $3^{+/-}$(open

decreased myocardial rates of glucose oxidation by $26 \%$ and also led to a 4.5-fold decrease in myocardial rates of oleate oxidation at baseline. These changes in substrate oxidation were accompanied by a decrease in $\mathrm{M} V_{O 2}$ and an improvement in cardiac efficiency for the $\mathrm{ucp} 3^{+/+}$hearts at baseline (Table 1). Following ischemia, contractile recovery of ucp $3^{+/+}$hearts was complete and sustained over the whole reperfusion period, although the recovery of aortic pressure was still delayed when compared to oleate $(190 \pm 33$ vs. $89 \pm 17 \mathrm{~s} ; p=0.01)$. Interestingly, the recovery of cardiac power occurred in the presence of an increase in rates of oleate oxidation (Fig. 7d). There was also a reduction in cardiac efficiency (Fig. 7f). For the UCP3-deficient hearts, the recovery of all cardiac parameters at reperfusion followed that of the ucp $3^{+/+}$ hearts (Fig. 7a-f). Consequently, and as for perfusion with octanoate alone, the recovery of cardiac power and $\mathrm{M} V_{O 2}$ was improved for ucp $3^{+/-}$hearts when compared to perfusion with oleate alone. Again, complete recovery of cardiac parameters was independent from improvement of time to recovery of aortic pressure post-ischemia $(191 \pm 26 \mathrm{~s} ; p=0.99$ vs. oleate $)$. squares, $n=8$ ) rats subjected to $\mathrm{MI} /$ reperfusion and incubated with $0.5 \mathrm{mM}$ oleate in the presence of the hydrogen peroxide probe Amplex Red. c-e The activity of the antioxidant enzymes catalase, superoxide dismutase (SOD), and glutathione peroxidase (Gpx) was measured in hearts from $\mathrm{ucp} 3^{+/+}(n=8)$ and $\mathrm{ucp}^{+/-}(n=10)$ rats. Data are presented as mean \pm SE. $* p<0.05$

The incubation of mitochondria isolated from ucp $3^{+/+}$ hearts with the octanoate/oleate mixture resulted in a $35 \%$ decrease in the rate of ADP-stimulated respiration when compared to incubation with oleate alone $(1.21 \pm 0.14 \mathrm{vs}$. $1.86 \pm 0.16 \mu \mathrm{mol} \mathrm{e}^{-} / \mathrm{min} / \mathrm{mg}$ protein; $\left.p=0.01\right)$. However, and as for mitochondria incubated with octanoate alone, the decrease in the rate of ADP-stimulated respiration did not lead to a decreased mitochondrial membrane potential (Fig. 7g). The combined supply of MCFA and LCFA also prevented a drop in the rate of ADP-stimulated respiration for $\mathrm{ucp}^{+/-}$cardiac mitochondria subjected to MI-reperfusion (Fig. 7h). Moreover, the burst of ROS generated post-ischemia by ucp $3^{+/-}$mitochondria was attenuated when compared to $\mathrm{ucp}^{+/-}$mitochondria supplied with oleate alone, so that ROS levels were now comparable to that produced by ucp $3^{+/+}$mitochondria (Fig. 7i). 
a
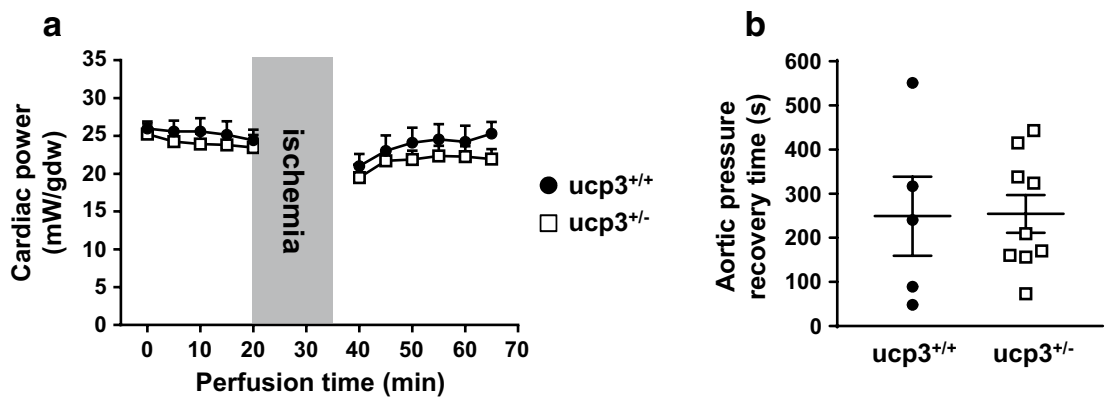

d

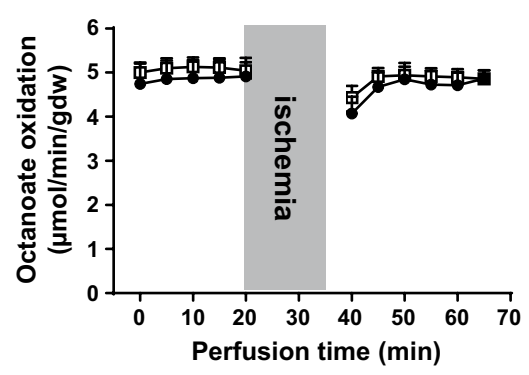

g

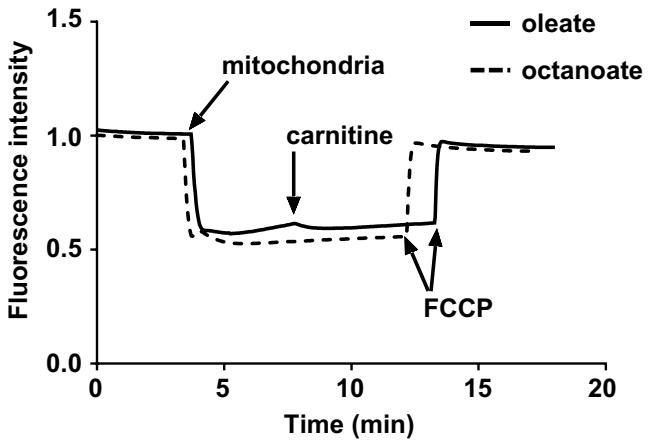

Fig. 6 Octanoate promotes contractile recovery and preserves mitochondrial function in ucp $3^{+/-}$hearts at reperfusion. Isolated hearts from ucp $3^{+/+}$control rats (black circles, $n=5$ ) and ucp $3^{+/-}$rats (open squares, $n=9-10$ ) were perfused in the working mode in the presence of $5.5 \mathrm{mM}$ glucose and $0.8 \mathrm{mM}$ of the MCFA octanoate as substrates. Cardiac power (a), time to recovery of aortic pressure post ischemia (b), rates of glucose oxidation (c), rates of octanoate oxidation (d), myocardial oxygen consumption (e), and cardiac efficiency (f) were determined as described in the "Methods" section. Data are presented as mean \pm SE. ${ }^{\dagger} p<0.05 \mathrm{ucp}^{+/-}$vs. baseline. g Mitochondrial membrane potentials measured with the fluorescent probe Safranin O when using $0.5 \mathrm{mM}$ oleate (plain line) or $0.5 \mathrm{mM}$ octanoate (hatched

\section{Discussion}

The goals of this study were to reexamine myocardial UCP3 expression in several rodent models of obesity, insulin resistance and type 2 diabetes, and to determine the consequences for cardiac adaptation to $\mathrm{I} / \mathrm{R}$. We found that UCP3 protein levels were systematically decreased in the hearts of mouse and rat models of obesity, insulin

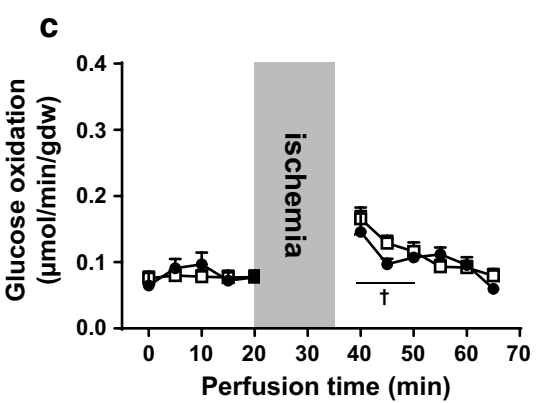

f

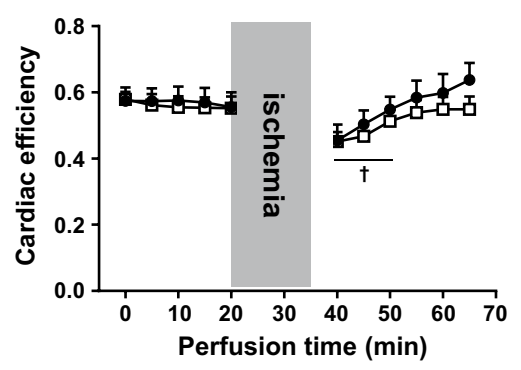

i

$\square$ oleate

LV infarct

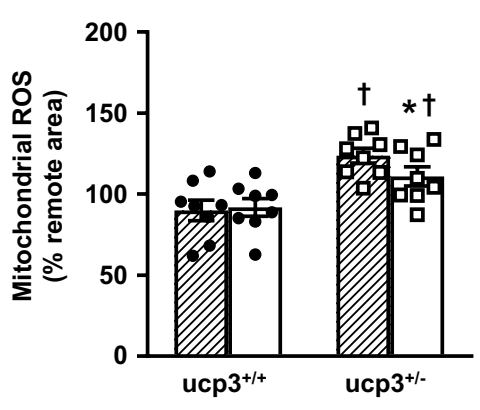

line) as substrates for ADP-stimulated respiration. FCCP, Carbonyl cyanide 4-(trifluoromethoxy)phenylhydrazone. h ADP-stimulated respiration in the presence of $0.5 \mathrm{mM}$ octanoate was measured for mitochondria isolated from the remote region (dotted bars) and the infarct area (open bars) of ucp $3^{+/+}(n=10)$ and ucp3 $3^{+/-}(n=10)$ rat hearts subjected to MI/reperfusion. i Comparison of ROS generation in mitochondria incubated with $0.5 \mathrm{mM}$ oleate (hatched bars) or $0.5 \mathrm{mM}$ octanoate (open bars) following isolation from the infarct area of ucp $3^{+/+}(n=8)$ and $\mathrm{ucp}^{+/-}(n=8)$ rat hearts subjected to MI/ reperfusion. Data are presented as mean \pm SE. $* p<0.05$ vs. oleate; ${ }^{\dagger} p<0.05$ vs. ucp ${ }^{+/+}$

resistance and type 2 diabetes. Through targeted mutation of one UCP3 gene copy in rats, we showed that partial myocardial UCP3 deficiency, resembling that which occurs with type 2 diabetes, was sufficient to severely impair the contractile recovery of ex vivo perfused hearts subjected to I/R. The decrease in contractile recovery was linked to mitochondrial dysfunction characterized by increased ROS generation, decreased respiratory complex 
a

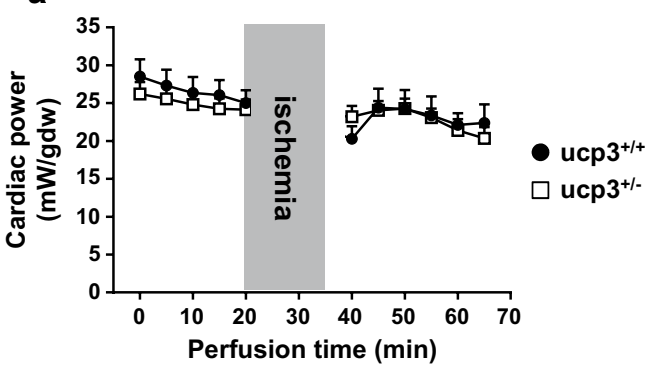

d

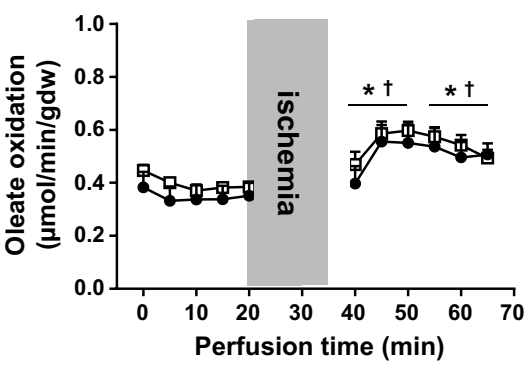

g

Mitochondrial Membrane Potential

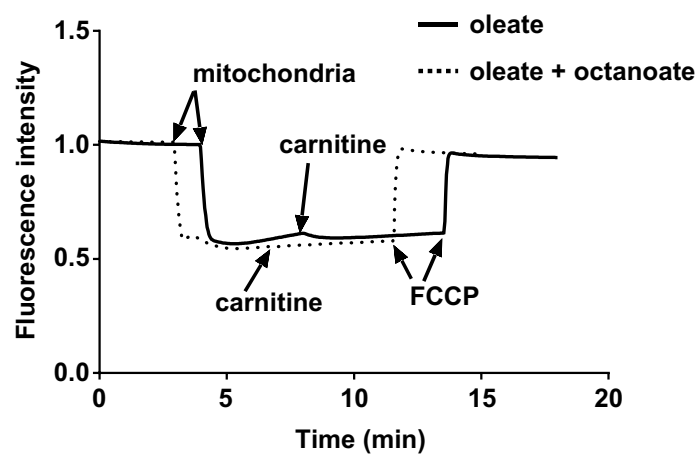

b

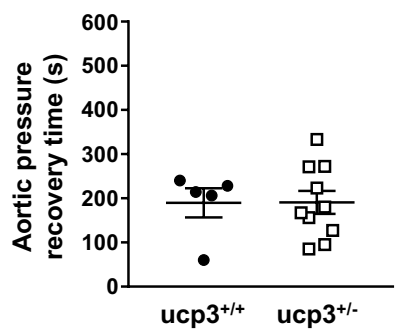

e

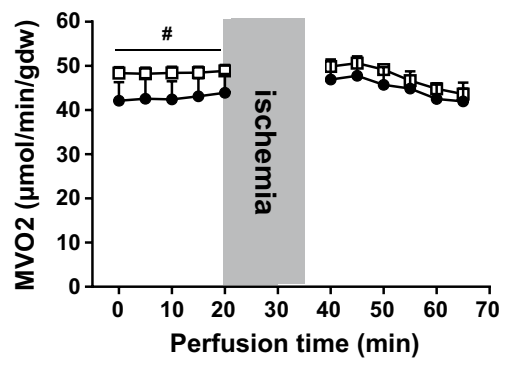

h

h $\square$ LV remote

LV infarct

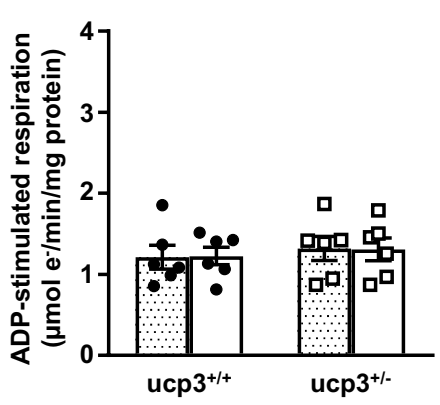

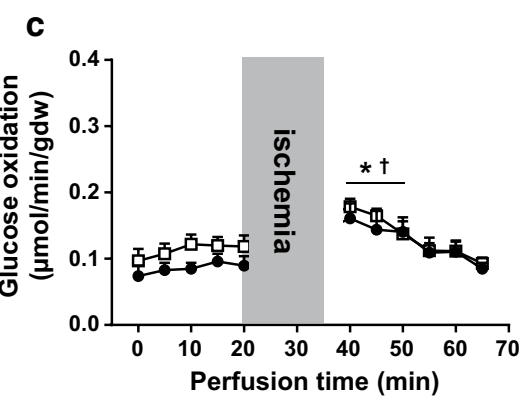

f

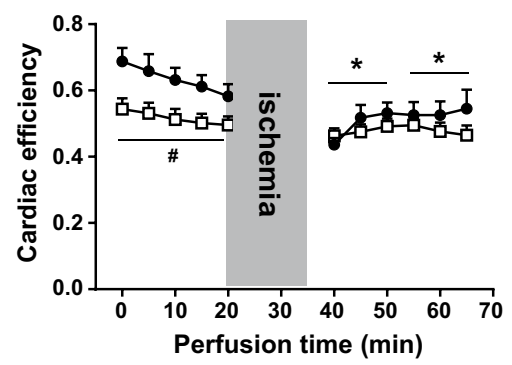

i

$\square$ oleate

oleate + octanoate

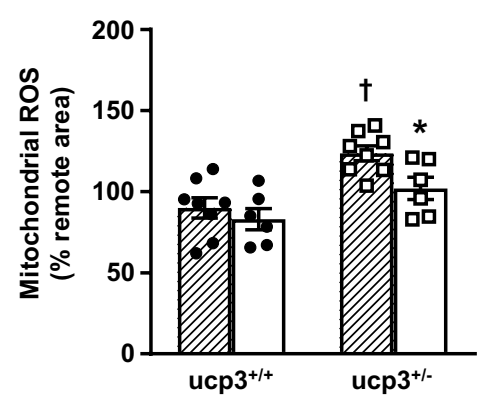

Fig. 7 Octanoate supplementation promotes contractile recovery and preserves oleate oxidation and mitochondrial function in $\mathrm{ucp}^{+/-}$hearts at reperfusion. Isolated hearts from ucp $3^{+/+}$control rats (black circles, $n=5$ ) and $\mathrm{ucp}^{+/-}$rats (open squares, $n=10-13$ ) were perfused in the working mode in the presence of $5.5 \mathrm{mM}$ glucose, $0.4 \mathrm{mM}$ oleate, and $0.4 \mathrm{mM}$ octanoate as substrates. Cardiac power (a), time to recovery of aortic pressure post ischemia (b), rates of glucose oxidation (c), rates of oleate oxidation (d), myocardial oxygen consumption (e), and cardiac efficiency (f) were determined as described in the "Methods" section. Data are presented as mean \pm SE. ${ }^{*} p<0.05 \mathrm{ucp}^{+/+}$vs. baseline; ${ }^{\dagger} p<0.05 \mathrm{ucp}^{+/-}$vs. baseline; ${ }^{\#} p<0.05$ vs. ucp $3^{+/+}$. g Mitochondrial membrane potentials measured with the fluorescent probe Safranin O when using $0.5 \mathrm{mM}$

I activity, and impaired LCFA oxidation capacity. We also demonstrated that supplying large amounts of the MCFA octanoate, alone or combined with the LCFA oleate, slowed the flow of electrons through the respiratory chain and decreased the generation of ROS in ucp $3^{+/-}$cardiac mitochondria. The use of octanoate also led to a decrease in myocardial rates of glucose oxidation and improved oleate (plain line) or $0.5 \mathrm{mM}$ of an equimolar mixture of oleate and octanoate (dotted line) as substrates for ADP-stimulated respiration. FCCP, Carbonyl cyanide 4-(trifluoromethoxy)phenylhydrazone. h ADP-stimulated respiration in the presence of $0.5 \mathrm{mM}$ of an equimolar mixture of oleate and octanoate was measured for mitochondria isolated from the remote region (dotted bars) and the infarct area (open bars) of ucp3 $3^{+/+}(n=6)$ and $\mathrm{ucp}^{+/-}(n=6)$ rat hearts subjected to $\mathrm{MI} /$ reperfusion. i Comparison of ROS generation in mitochondria incubated with $0.5 \mathrm{mM}$ oleate (hatched bars) or $0.5 \mathrm{mM}$ of an equimolar mixture of oleate and octanoate (open bars) following isolation from the infarct area of ucp3 $3^{+/+}(n=6-8)$ and $\mathrm{ucp}^{+/-}(n=6-8)$ rat hearts subjected to $\mathrm{MI} /$ reperfusion. Data are presented as mean $\pm \mathrm{SE}$. ${ }^{*} p<0.05$ vs. oleate; ${ }^{\dagger} p<0.05$ vs. ucp $3^{+/+}$

LCFA oxidation capacity at reperfusion. At the functional level, MCFA supplementation promoted complete recovery of contractile function for ucp $3^{+/-}$hearts following ischemia. 


\section{Impact of obesity, insulin resistance and type 2 diabetes on cardiac UCP3 levels}

The transcription factor peroxisome proliferator-activated receptor (PPAR)- $\alpha$ potently activates myocardial UCP3 expression in response to increased delivery of LCFAs to cardiomyocytes [45]. Because obesity and diabetes are associated with an increased supply of circulating fatty acids to the heart, myocardial UCP3 levels should increase under those conditions [51]. In fact, there is considerable evidence for increased myocardial UCP3 levels with high-fat feeding and with type 1 diabetes [17, 23, 28]. However, the impact of type 2 diabetes on myocardial UCP3 expression has remained controversial $[10,11]$. Insulin resistance and hyperinsulinemia play a central role in the metabolic disturbances associated with type 2 diabetes [61]. We previously reported a decrease in cardiac UCP3 protein levels in experimental rat and mouse models of hyperinsulinemia and insulin resistance [31, 32]. We also demonstrated that hyperinsulinemia triggers insulin resistance in the heart, which in turn induces lipogenic transcription factor SREBP-1 and subsequent down-regulation of UCP3 expression [31]. In the present study, we extended our investigations to monogenic rodent models of obesity, insulin resistance and type 2 diabetes and found that cardiac UCP3 protein levels were reduced between $20 \%$ and $49 \%$. Our findings of decreased UCP3 protein expression in the hearts of $o b / o b$ mice are consistent with a report from the Abel group [11]. Our results are also in line with the respective $46 \%$ and $35 \%$ decreases in UCP3 protein content observed in skeletal muscle of prediabetic and type 2 diabetic humans [59]. Thus, the data accumulated so far suggest that type 2 diabetes inhibits UCP 3 expression in myocytes, thereby leading to partial UCP3 protein deficiency in the heart.

\section{Effect of partial UCP3 deficiency on cardiac recovery following I/R}

Rats fed a high-sucrose diet become insulin resistant and display, on average, a 40\% decrease in cardiac UCP3 content. Isolated working hearts from these rats exhibit a significant decrease in rates of LCFA oxidation and a severe impairment of contractile recovery when subjected to I/R [33]. The Russell group and the Esposito group demonstrated a cardioprotective role for UCP3 for ischemic heart disease. Using ucp $3^{-1-}$ mice, these groups found a decrease in myocardial ATP content in response to $\mathrm{I} / \mathrm{R}$, a $50 \%$ increase in infarct size post MI, higher rates of apoptosis, and worsening of contractile function when compared to wild-type mice. Both teams posited that increased ROS were responsible for the increased failure of hearts lacking UCP3 [53, 55]. However, insulin resistance and type 2 diabetes are associated with only a partial deficiency in UCP3, and it remained unknown if a partial deficiency was sufficient to make the heart more vulnerable to MI and I/R injury. Here, we have used CRISPR/Cas9-targeted mutagenesis to inactivate one copy of the UCP3 gene in rats to explore this question. Although hearts from ucp $3^{+/-}$rats had normal metabolic and contractile functions under basal perfusion conditions, myocardial rates of LCFA oxidation and cardiac power were dramatically impaired in response to $\mathrm{I} / \mathrm{R}$. An increased accumulation of lipid droplets in ucp $3^{+/}$cardiomyocytes indicated impairment of LCFA utilization at reperfusion. Thus, partial UCP3 deficiency is sufficient to impair myocardial LCFA metabolism and contractile recovery at reperfusion.

\section{Partial loss of UCP3 and impairment of myocardial LCFA oxidation}

LCFAs are the preferred substrate for energy production in the heart when the supply of oxygen is not limited [64]. There exists compelling evidence that the mild uncoupling activity of UCP3 is a consequence of its regulation of fatty acid utilization [14]. Thus, mild overexpression of UCP3 increases LCFA oxidation in rat L6 myocytes and in skeletal muscle of mice $[9,46]$. The accumulation of lipid droplets in ucp $3^{+/-}$cardiomyocytes suggested either an impairment of the import of LCFA into mitochondria or decreased metabolic flux further downstream, in $\beta$-oxidation or oxidative phosphorylation. The fact that CPT1 activity remained unchanged in perfused hearts pointed towards the latter.

During $\mathrm{I} / \mathrm{R}$, loss of $\mathrm{pH}$ gradient and membrane potential both contribute to enhanced superoxide generation by cardiac mitochondria [38]. As mentioned above, ROS production is increased in cardiac mitochondria from mice lacking $\mathrm{UCP} 3$ in response to $\mathrm{I} / \mathrm{R}[53,67]$. Consistent with those reports, we observed increased mitochondrial ROS generation in UCP3-deficient rat cardiomyocytes subjected to a brief period of oxygen deprivation. Because UCP3 deficiency was not associated with a compensatory increase in cellular antioxidant defenses, the increased burst of ROS is likely to have caused oxidative damage within mitochondria during reperfusion. Subsarcolemmal mitochondria, which normally contain higher UCP3 levels, are especially affected by I/R-induced damage due to their exposure to higher oxygen levels [27, 37]. In particular, complex I has been identified as a primary target for oxidative damage in the mammalian heart post ischemia, resulting in decreased activity or outright inactivation of some of the enzyme [30, 54, 56]. Indeed, we found that complex I activity was decreased in $\mathrm{ucp}^{+/-}$mitochondria following I/R. Inhibition of complex I leads to NADH accumulation and to an increase in cellular $\mathrm{NADH} / \mathrm{NAD}^{+}$[58]. The NADH/NAD ${ }^{+}$balance exerts tight control over $\beta$-oxidation flux so that fatty acid oxidation is inhibited when NADH/NAD ${ }^{+}$rises [26]. Hence, our findings suggest that the increased burst of mitochondrial ROS 
during reperfusion of the ucp $3^{+/-}$hearts may have inactivated some of the complex I, increased NADH/NAD ${ }^{+}$, and, thereby, decreased the flux of LCFA through $\beta$-oxidation. Decreased rates of oxidative phosphorylation driven by LCFA would, in turn, limit ATP production and the contractile recovery of the ucp $3^{+/-}$heart (Fig. 8).

\section{MCFA supplementation as a therapeutic intervention for the UCP3-deficient heart post ischemia}

We have shown that the contractile dysfunction induced ex vivo by $I / R$ in hearts of insulin-resistant rats could be prevented by replacing the LCFA oleate with the MCFA octanoate in the perfusion buffer [33]. In the present study, we also observed a protective effect of octanoate for the $\mathrm{ucp}^{+/-}$heart. Moreover, perfusing hearts with an equimolar mixture of octanoate and oleate also promoted full recovery of contractile function. Although LCFAs constitute the bulk of circulating fatty acids and the primary substrate for the healthy mammalian heart, MCFAs can be readily oxidized by the heart as well. Our findings are consistent with previous studies demonstrating that MCFAs can restore function in hearts that have an impaired capacity to utilize LCFAs. The metabolism of MCFAs in stressed hearts has been shown to restore a normal glucose-to-fat oxidation balance and to increase ATP generation [41]. In hearts from spontaneously hypertensive rats subjected to an acute increase in workload, MCFA oxidation compensates for decreased capacity to utilize exogenous LCFAs [42]. In hypertrophied hearts from aortic-constricted rats, addition of octanoate (C8:0) to palmitate $(\mathrm{C} 16: 0)$ in the perfusate leads to increased ATP generation [5]. Moreover, MCFAs greatly enhance post-ischemic recovery of hearts from CD36-null mice, which have decreased capacity to take up LCFAs [36].

Four important features distinguished hearts that were perfused in the presence of octanoate from hearts that were perfused with oleate alone: (1) decreased rates of glucose oxidation, especially in the first minutes of reperfusion; (2) slower mitochondrial rates of ADP-stimulated respiration; (3) increased time to recovery of aortic pressure post-ischemia, and (4) mitigation of mitochondrial ROS generation during reperfusion in UCP3-deficient hearts. Taken together, those features seem to indicate a metabolic slowdown associated with MCFA oxidation at reperfusion. This metabolic slowdown may prove beneficial in preserving mitochondrial function and promoting contractile recovery for the ucp $3^{+/-}$hearts. There is mounting evidence that rapid recovery of mitochondrial respiration in the post-ischemic period promotes damage to the oxidative phosphorylation

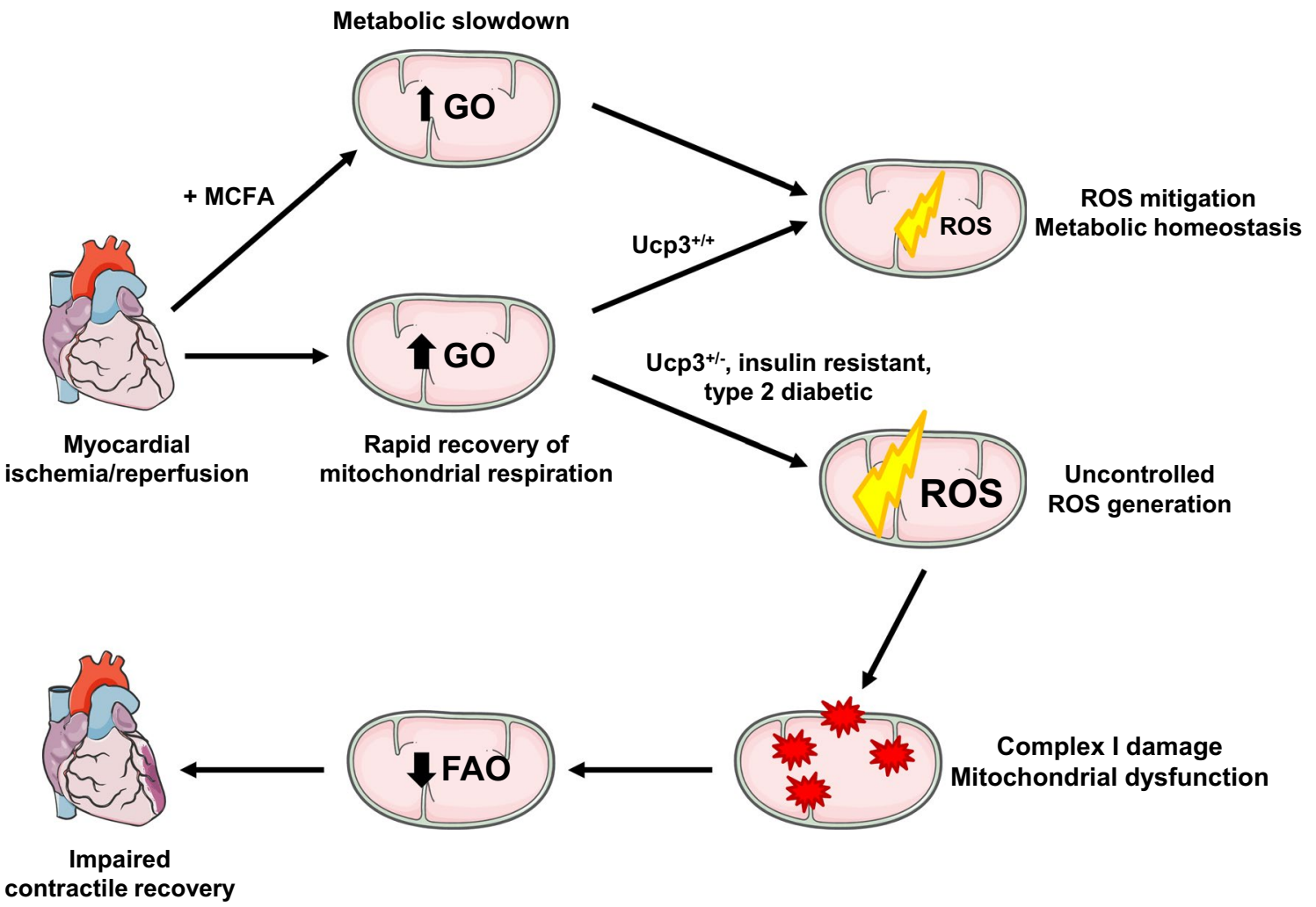

Fig. 8 Proposed mechanism for the postischemic impairment of cardiac contractile recovery caused by UCP3 deficiency and its prevention with medium-chain fatty acid (MCFA) supplementation. FAO fatty acid oxidation, GO glucose oxidation 
machinery that impedes full recovery of cardiac function. For example, high glucose utilization during reperfusion can accelerate electron transfer through a respiratory chain that has sustained oxidative damage, a situation that increases the production of superoxide and downstream ROS [16]. In healthy hearts, the use of respiratory chain inhibitors to block electron transport during ischemia and reperfusion has proven to be cardioprotective $[4,21]$. Reversible inhibition of complex I activity limits oxyradical production by decreasing electron flow into complex III and by decreasing reverse electron transport from complex II to complex I [20, 50]. In this case, the wash-out of inhibitors at reperfusion is believed to afford protection by facilitating a more gradual recovery of mitochondrial function, thereby avoiding a burst of ROS and $\mathrm{Ca}^{2+}$ overload in mitochondria [18]. Since a high membrane potential can contribute to ROS production, the activation of UCPs during increased rates of electron transfer serves a physiological role by slightly decreasing the membrane potential $[13,14]$. Thus, we propose that MCFAs may compensate for a partial lack of myocardial UCP3 at reperfusion by preventing excessive mitochondrial respiration and ROS-mediated mitochondrial dysfunction (Fig. 8).

In conclusion, our results demonstrate that normal UCP3 protein levels are a critical determinant of optimal recovery of mitochondrial LCFA oxidation and contractility in the post-ischemic heart. Moreover, our findings reveal a potential mechanism for the increased sensitivity of obese, insulin-resistant type 2 diabetic individuals toward I/R injury. We acknowledge that the main energetic problem for the diabetic heart has historically been attributed to the impairment of glucose oxidation $[1,47,48]$. Although therapies promoting glucose oxidation (e.g. GIK, rosiglitazone) can improve functional recovery of the diabetic heart after ischemia [29, 35], adverse effects (hyperglycemia, cardiovascular events) may outweigh clinical benefits of such strategies [22, 40, 52]. Matching fatty acid metabolism to the energetic needs of the heart has been proposed as an alternative intervention to preserve cardiac function in pathological situations [39]. We propose that reperfusion with MCFAs may be an effective metabolic intervention for improving the recovery of the type 2 diabetic heart following ischemia.

Acknowledgements This work was supported by Grants R00 HL112952, R01 HL136438, P01 HL051971, and P20 GM104357 from the National Institutes of Health. M.E.H. is supported by Career Development Award K08 DK099415 from the National Institutes of Health. The content of this work is solely the responsibility of the authors and does not necessarily represent the official views of the National Institutes of Health. The authors thank Dr. Jussara do Carmo for providing hearts tissue samples from loxTB MC4R ${ }^{-/-}$mice, LepR/ Nestin-cre mice, and MC4RKO rats. We thank Glenn A. Hoskins and Rebecca J. Potter for their technical assistance with the preparation and analysis of transmission electron microscopy samples. We are grateful to Dr. Barbara T. Alexander and Haiyan Zhang from the Analytical and Assay Core of the Department of Physiology and Biophysics at
UMMC for assaying plasma insulin and leptin samples. Figure 8 was drawn in part with Smart Servier Medical Art artwork created by LES LABORATOIRES SERVIER, SAS.

\section{Compliance with ethical standards}

Conflict of interest The authors declare that they have no conflict of interest.

Open Access This article is distributed under the terms of the Creative Commons Attribution 4.0 International License (http://creativecommons.org/licenses/by/4.0/), which permits unrestricted use, distribution, and reproduction in any medium, provided you give appropriate credit to the original author(s) and the source, provide a link to the Creative Commons license, and indicate if changes were made.

\section{References}

1. Aasum E, Hafstad AD, Severson DL, Larsen TS (2003) Agedependent changes in metabolism, contractile function, and ischemic sensitivity in hearts from $\mathrm{db} / \mathrm{db}$ mice. Diabetes 52:434441. https://doi.org/10.2337/diabetes.52.2.434

2. Abbasi F, Brown BW Jr, Lamendola C, McLaughlin T, Reaven GM (2002) Relationship between obesity, insulin resistance, and coronary heart disease risk. J Am Coll Cardiol 40:937-943. https ://doi.org/10.1016/S0735-1097(02)02051-X

3. Ackers-Johnson M, Li PY, Holmes AP, O’Brien SM, Pavlovic D, Foo RS (2016) A simplified, Langendorff-free method for concomitant isolation of viable cardiac myocytes and nonmyocytes from the adult mouse heart. Circ Res 119:909-920. https://doi. org/10.1161/CIRCRESAHA.116.309202

4. Aldakkak M, Stowe DF, Chen Q, Lesnefsky EJ, Camara AK (2008) Inhibited mitochondrial respiration by amobarbital during cardiac ischaemia improves redox state and reduces matrix $\mathrm{Ca}^{2+}$ overload and ROS release. Cardiovasc Res 77:406-415. https:// doi.org/10.1016/j.cardiores.2007.08.008

5. Allard MF, Parsons HL, Saeedi R, Wambolt RB, Brownsey R (2007) AMPK and metabolic adaptation by the heart to pressure overload. Am J Physiol Heart Circ Physiol 292:H140-H148. https ://doi.org/10.1152/ajpheart.00424.2006

6. Bakrania B, Granger JP, Harmancey R (2016) Methods for the determination of rates of glucose and fatty acid oxidation in the isolated working rat heart. J Vis Exp 1:1. https://doi. org/10.3791/54497

7. Bassi M, Nakamura NB, Furuya WI, Colombari DS, Menani JV, do Carmo JM, da Silva AA, Hall JE, Colombari E (2015) Activation of the brain melanocortin system is required for leptininduced modulation of chemorespiratory function. Acta Physiol (Oxf) 213:893-901. https://doi.org/10.1111/apha.12394

8. Baumann RP, Penketh PG, Seow HA, Shyam K, Sartorelli AC (2008) Generation of oxygen deficiency in cell culture using a two-enzyme system to evaluate agents targeting hypoxic tumor cells. Radiat Res 170:651-660. https://doi.org/10.1667/RR1431.1

9. Bezaire V, Spriet LL, Campbell S, Sabet N, Gerrits M, Bonen A, Harper ME (2005) Constitutive UCP3 overexpression at physiological levels increases mouse skeletal muscle capacity for fatty acid transport and oxidation. FASEB J 19:977-979. https://doi. org/10.1096/fj.04-2765fje

10. Boudina S, Abel ED (2006) Mitochondrial uncoupling: a key contributor to reduced cardiac efficiency in diabetes. Physiology (Bethesda) 21:250-258. https://doi.org/10.1152/physiol.00008 .2006 
11. Boudina S, Han YH, Pei S, Tidwell TJ, Henrie B, Tuinei J, Olsen C, Sena S, Abel ED (2012) UCP3 regulates cardiac efficiency and mitochondrial coupling in high fat-fed mice but not in leptindeficient mice. Diabetes 61:3260-3269. https://doi.org/10.2337/ db12-0063

12. Boudina S, Sena S, Theobald H, Sheng X, Wright JJ, Hu XX, Aziz S, Johnson JI, Bugger H, Zaha VG, Abel ED (2007) Mitochondrial energetics in the heart in obesity-related diabetes: direct evidence for increased uncoupled respiration and activation of uncoupling proteins. Diabetes 56:2457-2466. https://doi.org/10.2337/ db07-0481

13. Brand MD, Affourtit C, Esteves TC, Green K, Lambert AJ, Miwa S, Pakay JL, Parker N (2004) Mitochondrial superoxide: production, biological effects, and activation of uncoupling proteins. Free Radic Biol Med 37:755-767. https://doi.org/10.1016/j.freeradbio med.2004.05.034

14. Brand MD, Esteves TC (2005) Physiological functions of the mitochondrial uncoupling proteins UCP2 and UCP3. Cell Metab 2:85-93. https://doi.org/10.1016/j.cmet.2005.06.002

15. Brener SJ, Mehran R, Dressler O, Cristea E, Stone GW (2012) Diabetes mellitus, myocardial reperfusion, and outcome in patients with acute ST-elevation myocardial infarction treated with primary angioplasty (from HORIZONS AMI). Am J Cardiol 109:1111-1116. https://doi.org/10.1016/j.amjcard.2011.11.046

16. Brownlee M (2001) Biochemistry and molecular cell biology of diabetic complications. Nature 414:813-820. https://doi. org/10.1038/414813a

17. Bugger H, Boudina S, Hu XX, Tuinei J, Zaha VG, Theobald HA, Yun UJ, McQueen AP, Wayment B, Litwin SE, Abel ED (2008) Type 1 diabetic akita mouse hearts are insulin sensitive but manifest structurally abnormal mitochondria that remain coupled despite increased uncoupling protein 3. Diabetes 57:2924-2932. https://doi.org/10.2337/db08-0079

18. Burwell LS, Nadtochiy SM, Brookes PS (2009) Cardioprotection by metabolic shut-down and gradual wake-up. J Mol Cell Cardiol 46:804-810. https://doi.org/10.1016/j.yjmcc.2009.02.026

19. Carson JL, Scholz PM, Chen AY, Peterson ED, Gold J, Schneider SH (2002) Diabetes mellitus increases short-term mortality and morbidity in patients undergoing coronary artery bypass graft surgery. J Am Coll Cardiol 40:418-423. https://doi.org/10.1016/ S0735-1097(02)01969-1

20. Chen Q, Moghaddas S, Hoppel CL, Lesnefsky EJ (2006) Reversible blockade of electron transport during ischemia protects mitochondria and decreases myocardial injury following reperfusion. J Pharmacol Exp Ther 319:1405-1412. https://doi.org/10.1124/ jpet.106.110262

21. Chen Q, Younus M, Thompson J, Hu Y, Hollander JM, Lesnefsky EJ (2018) Intermediary metabolism and fatty acid oxidation: novel targets of electron transport chain-driven injury during ischemia and reperfusion. Am J Physiol Heart Circ Physiol 314:H787H795. https://doi.org/10.1152/ajpheart.00531.2017

22. Chen X, Yang L, Zhai SD (2012) Risk of cardiovascular disease and all-cause mortality among diabetic patients prescribed rosiglitazone or pioglitazone: a meta-analysis of retrospective cohort studies. Chin Med J (Engl) 125:4301-4306. https://doi. org/10.3760/cma.j.issn.0366-6999.2012.23.025

23. Cole MA, Murray AJ, Cochlin LE, Heather LC, McAleese S, Knight NS, Sutton E, Jamil AA, Parassol N, Clarke K (2011) A high fat diet increases mitochondrial fatty acid oxidation and uncoupling to decrease efficiency in rat heart. Basic Res Cardiol 106:447-457. https://doi.org/10.1007/s00395-011-0156-1

24. Creager MA, Luscher TF, Cosentino F, Beckman JA (2003) Diabetes and vascular disease: pathophysiology, clinical consequences, and medical therapy: part I. Circulation 108:1527-1532. https://doi.org/10.1161/01.CIR.0000091257.27563.32
25. Despres JP, Lamarche B, Mauriege P, Cantin B, Dagenais GR, Moorjani S, Lupien PJ (1996) Hyperinsulinemia as an independent risk factor for ischemic heart disease. N Engl J Med 334:952957. https://doi.org/10.1056/NEJM199604113341504

26. Eaton S (2002) Control of mitochondrial beta-oxidation flux. Prog Lipid Res 41:197-239

27. Garcia-Nino WR, Correa F, Rodriguez-Barrena JI, Leon-Contreras JC, Buelna-Chontal M, Soria-Castro E, Hernandez-Pando R, Pedraza-Chaverri J, Zazueta C (2017) Cardioprotective kinase signaling to subsarcolemmal and interfibrillar mitochondria is mediated by caveolar structures. Basic Res Cardiol 112:15. https://doi.org/10.1007/s00395-017-0607-4

28. Gerber LK, Aronow BJ, Matlib MA (2006) Activation of a novel long-chain free fatty acid generation and export system in mitochondria of diabetic rat hearts. Am J Physiol Cell Physiol 291:C1198-C1207. https://doi.org/10.1152/ajpcell.00246.2006

29. Hafstad AD, Khalid AM, How OJ, Larsen TS, Aasum E (2007) Glucose and insulin improve cardiac efficiency and postischemic functional recovery in perfused hearts from type 2 diabetic (db/db) mice. Am J Physiol Endocrinol Metab 292:E1288E1294. https://doi.org/10.1152/ajpendo.00504.2006

30. Hardy DL, Clark JB, Darley-Usmar VM, Smith DR (1990) Reoxygenation of the hypoxic myocardium causes a mitochondrial complex I defect. Biochem Soc Trans 18:549. https://doi. org/10.1042/bst0180549

31. Harmancey R, Haight DL, Watts KA, Taegtmeyer H (2015) Chronic hyperinsulinemia causes selective insulin resistance and down-regulates uncoupling protein 3 (UCP3) through the activation of sterol regulatory element-binding protein (SREBP)-1 transcription factor in the mouse heart. J Biol Chem 290:30947-30961. https://doi.org/10.1074/jbc.M115.673988

32. Harmancey R, Lam TN, Lubrano GM, Guthrie PH, Vela D, Taegtmeyer H (2012) Insulin resistance improves metabolic and contractile efficiency in stressed rat heart. FASEB J 26:31183126. https://doi.org/10.1096/fj.12-208991

33. Harmancey R, Vasquez HG, Guthrie PH, Taegtmeyer H (2013) Decreased long-chain fatty acid oxidation impairs postischemic recovery of the insulin-resistant rat heart. FASEB J 27:39663978. https://doi.org/10.1096/fj.13-234914

34. Hidaka S, Kakuma T, Yoshimatsu H, Sakino H, Fukuchi S, Sakata T (1999) Streptozotocin treatment upregulates uncoupling protein 3 expression in the rat heart. Diabetes 48:430-435. https://doi.org/10.2337/diabetes.48.2.430

35. How OJ, Larsen TS, Hafstad AD, Khalid A, Myhre ES, Murray AJ, Boardman NT, Cole M, Clarke K, Severson DL, Aasum E (2007) Rosiglitazone treatment improves cardiac efficiency in hearts from diabetic mice. Arch Physiol Biochem 113:211-220. https://doi.org/10.1080/13813450701783281

36. Irie H, Krukenkamp IB, Brinkmann JF, Gaudette GR, Saltman AE, Jou W, Glatz JF, Abumrad NA, Ibrahimi A (2003) Myocardial recovery from ischemia is impaired in CD36-null mice and restored by myocyte CD36 expression or medium-chain fatty acids. Proc Natl Acad Sci USA 100:6819-6824. https:// doi.org/10.1073/pnas.1132094100

37. Jimenez M, Yvon C, Lehr L, Leger B, Keller P, Russell A, Kuhne F, Flandin P, Giacobino JP, Muzzin P (2002) Expression of uncoupling protein-3 in subsarcolemmal and intermyofibrillar mitochondria of various mouse muscle types and its modulation by fasting. Eur J Biochem 269:2878-2884

38. Kang PT, Chen CL, Lin P, Chilian WM, Chen YR (2017) Impairment of $\mathrm{pH}$ gradient and membrane potential mediates redox dysfunction in the mitochondria of the post-ischemic heart. Basic Res Cardiol 112:36. https://doi.org/10.1007/s0039 5-017-0626-1

39. Kerr M, Dodd MS, Heather LC (2017) The 'Goldilocks zone' of fatty acid metabolism; to ensure that the relationship with cardiac 
function is just right. Clin Sci (Lond) 131:2079-2094. https://doi. org/10.1042/CS20160671

40. Kloner RA, Nesto RW (2008) Glucose-insulin-potassium for acute myocardial infarction: continuing controversy over cardioprotection. Circulation 117:2523-2533. https://doi.org/10.1161/CIRCU LATIONAHA.107.697979

41. Labarthe F, Gelinas R, Des Rosiers C (2008) Medium-chain fatty acids as metabolic therapy in cardiac disease. Cardiovasc Drugs Ther 22:97-106. https://doi.org/10.1007/s10557-008-6084-0

42. Labarthe F, Khairallah M, Bouchard B, Stanley WC, Des Rosiers C (2005) Fatty acid oxidation and its impact on response of spontaneously hypertensive rat hearts to an adrenergic stress: benefits of a medium-chain fatty acid. Am J Physiol Heart Circ Physiol 288:H1425-H1436. https://doi.org/10.1152/ajpheart.00722.2004

43. Leon BM, Maddox TM (2015) Diabetes and cardiovascular disease: epidemiology, biological mechanisms, treatment recommendations and future research. World J Diabetes 6:1246-1258. https ://doi.org/10.4239/wjd.v6.i13.1246

44. Lindsey ML, Bolli R, Canty JM Jr, Du XJ, Frangogiannis NG, Frantz S, Gourdie RG, Holmes JW, Jones SP, Kloner RA, Lefer DJ, Liao R, Murphy E, Ping P, Przyklenk K, Recchia FA, Schwartz Longacre L, Ripplinger CM, Van Eyk JE, Heusch G (2018) Guidelines for experimental models of myocardial ischemia and infarction. Am J Physiol Heart Circ Physiol 314:H812-H838. https://doi.org/10.1152/ajpheart.00335.2017

45. Lockridge JB, Sailors ML, Durgan DJ, Egbejimi O, Jeong WJ, Bray MS, Stanley WC, Young ME (2008) Bioinformatic profiling of the transcriptional response of adult rat cardiomyocytes to distinct fatty acids. J Lipid Res 49:1395-1408. https://doi. org/10.1194/jlr.M700517-JLR200

46. MacLellan JD, Gerrits MF, Gowing A, Smith PJ, Wheeler MB, Harper ME (2005) Physiological increases in uncoupling protein 3 augment fatty acid oxidation and decrease reactive oxygen species production without uncoupling respiration in muscle cells. Diabetes 54:2343-2350. https://doi.org/10.2337/diabetes.54.8.2343

47. Mather KJ, Lteif AA, Veeneman E, Fain R, Giger S, Perry K, Hutchins GD (2010) Role of endogenous ET-1 in the regulation of myocardial blood flow in lean and obese humans. Obesity (Silver Spring) 18:63-70. https://doi.org/10.1038/oby.2009.196

48. Mazumder PK, O’Neill BT, Roberts MW, Buchanan J, Yun UJ, Cooksey RC, Boudina S, Abel ED (2004) Impaired cardiac efficiency and increased fatty acid oxidation in insulin-resistant ob/ ob mouse hearts. Diabetes 53:2366-2374. https://doi.org/10.2337/ diabetes.53.9.2366

49. Munusamy S, do Carmo JM, Hosler JP, Hall JE (2015) Obesityinduced changes in kidney mitochondria and endoplasmic reticulum in the presence or absence of leptin. Am J Physiol Renal Physiol 309:F731-F743. https://doi.org/10.1152/ajprenal.00188 .2015

50. Murphy MP (2009) How mitochondria produce reactive oxygen species. Biochem J 417:1-13. https://doi.org/10.1042/BJ200 81386

51. Murray AJ, Panagia M, Hauton D, Gibbons GF, Clarke K (2005) Plasma free fatty acids and peroxisome proliferator-activated receptor alpha in the control of myocardial uncoupling protein levels. Diabetes 54:3496-3502. https://doi.org/10.2337/diabe tes.54.12.3496

52. Nissen SE, Wolski K (2007) Effect of rosiglitazone on the risk of myocardial infarction and death from cardiovascular causes. N Engl J Med 356:2457-2471. https://doi.org/10.1056/NEJMo a072761

53. Ozcan C, Palmeri M, Horvath TL, Russell KS, Russell RR 3rd (2013) Role of uncoupling protein 3 in ischemia-reperfusion injury, arrhythmias, and preconditioning. Am J Physiol Heart Circ Physiol 304:H1192-H1200. https://doi.org/10.1152/ajphe art.00592.2012
54. Paradies G, Petrosillo G, Pistolese M, Di Venosa N, Federici A, Ruggiero FM (2004) Decrease in mitochondrial complex I activity in ischemic/reperfused rat heart: involvement of reactive oxygen species and cardiolipin. Circ Res 94:53-59. https://doi. org/10.1161/01.RES.0000109416.56608.64

55. Perrino C, Schiattarella GG, Sannino A, Pironti G, Petretta MP, Cannavo A, Gargiulo G, Ilardi F, Magliulo F, Franzone A, Carotenuto G, Serino F, Altobelli GG, Cimini V, Cuocolo A, Lombardi A, Goglia F, Indolfi C, Trimarco B, Esposito G (2013) Genetic deletion of uncoupling protein 3 exaggerates apoptotic cell death in the ischemic heart leading to heart failure. J Am Heart Assoc 2:e000086. https://doi.org/10.1161/JAHA.113.000086

56. Rouslin W, Millard RW (1980) Canine myocardial ischemia: defect in mitochondrial electron transfer complex I. J Mol Cell Cardiol 12:639-645. https://doi.org/10.1016/0022-2828(80)90021 $-8$

57. Rowley WR, Bezold C, Arikan Y, Byrne E, Krohe S (2017) Diabetes 2030: insights from yesterday, today, and future trends. Popul Health Manag 20:6-12. https://doi.org/10.1089/pop.2015.0181

58. Santidrian AF, Matsuno-Yagi A, Ritland M, Seo BB, LeBoeuf SE, Gay LJ, Yagi T, Felding-Habermann B (2013) Mitochondrial complex I activity and $\mathrm{NAD}^{+} / \mathrm{NADH}$ balance regulate breast cancer progression. J Clin Investig 123:1068-1081. https://doi. org/10.1172/JCI64264

59. Schrauwen P, Mensink M, Schaart G, Moonen-Kornips E, Sels JP, Blaak EE, Russell AP, Hesselink MK (2006) Reduced skeletal muscle uncoupling protein-3 content in prediabetic subjects and type 2 diabetic patients: restoration by rosiglitazone treatment. J Clin Endocrinol Metab 91:1520-1525. https://doi.org/10.1210/ jc.2005-1572

60. Senese R, Valli V, Moreno M, Lombardi A, Busiello RA, Cioffi F, Silvestri E, Goglia F, Lanni A, de Lange P (2011) Uncoupling protein 3 expression levels influence insulin sensitivity, fatty acid oxidation, and related signaling pathways. Pflugers Arch 461:153164. https://doi.org/10.1007/s00424-010-0892-3

61. Shanik MH, Xu Y, Skrha J, Dankner R, Zick Y, Roth J (2008) Insulin resistance and hyperinsulinemia: is hyperinsulinemia the cart or the horse? Diabetes Care 31(Suppl 2):S262-S268. https:// doi.org/10.2337/dc08-s264

62. Shirey K, Stover KR, Cleary J, Hoang N, Hosler J (2016) Membrane-anchored cyclic peptides as effectors of mitochondrial oxidative phosphorylation. Biochemistry 55:2100-2111. https://doi. org/10.1021/acs.biochem.5b01368

63. Smith SC Jr, Faxon D, Cascio W, Schaff H, Gardner T, Jacobs A, Nissen S, Stouffer R (2002) Prevention conference VI: diabetes and cardiovascular disease: Writing Group VI: revascularization in diabetic patients. Circulation 105:e165-e169. https://doi. org/10.1161/01.CIR.0000013957.30622.05

64. Stanley WC, Recchia FA, Lopaschuk GD (2005) Myocardial substrate metabolism in the normal and failing heart. Physiol Rev 85:1093-1129. https://doi.org/10.1152/physrev.00006.2004

65. Stepp DW, Osakwe CC, Belin de Chantemele EJ, Mintz JD (2013) Vascular effects of deletion of melanocortin-4 receptors in rats. Physiol Rep 1:e00146. https://doi.org/10.1002/phy2.146

66. Szabo Z, Hakanson E, Svedjeholm R (2002) Early postoperative outcome and medium-term survival in 540 diabetic and 2239 nondiabetic patients undergoing coronary artery bypass grafting. Ann Thorac Surg 74:712-719. https://doi.org/10.1016/S0003 $-4975(02) 03778-5$

67. Vidal-Puig AJ, Grujic D, Zhang CY, Hagen T, Boss O, Ido Y, Szczepanik A, Wade J, Mootha V, Cortright R, Muoio DM, Lowell BB (2000) Energy metabolism in uncoupling protein 3 gene knockout mice. J Biol Chem 275:16258-16266. https://doi. org/10.1074/jbc.M910179199 